\title{
The Effect of Change in GDP on FDI in the Saudi Oil Sector Using the Adhocks Model of the Lagged External Variables, for Period, 1994-2017 an Econometrics Study
}

\author{
Mohammed Radhi Jaafar \\ University of Maysan, Faculty of Management and Economics \\ Mhamedd4@gmail.com \\ Adnan Dawood M.AL-Ethary \\ University of Kufa, Faculty of Management and Economics \\ Adnan.daledary@uokufa.edu.iq \\ Skuna100@yahoo.com
}

\section{ARTICLE INFO}

Submission date: $13 / 8 / 2018$

Acceptance date: $1 / 11 / 2018$

Publication date: 10/3/2019

\begin{abstract}
The importance of foreign direct investment (FDI) to the Saudi oil sector, like other countries in the world, which is considered one of the important and complementary sources of domestic investment, is very important. FDI is no longer only about the transfer of capital, but is also a necessary source of knowledge transfer in modern management. The transfer of advanced technology, the training and development of local technical cadres and the creation of more jobs for citizens. However, there is a decline in the degree of openness of the legislative environment attractive to foreign direct investment in terms of transparency, in spite of the available legal and administrative legislation in Saudi Arabia, as the volume of foreign investment flowing into the Saudi oil sector has fluctuated and instability of annual decay rates for several reasons, The rate of change in GDP during the period 1990-2000 was only increasing in some years as a result of the first Gulf crisis, depriving Iraq of the oil resource and increasing the production of Saudi Arabia to compensate for the shortage in the oil market and so the increase was after the second Gulf war in 2003 The rate of change has increased steadily due to the shortage after the United Nations exported Iraqi oil in the oil-for-food agreement, in addition to the rising oil prices, which led to an increase in Saudi oil production and consequently increased the rate of change in GDP, In the estimated model in the eighth phase of Table 3, the data were tested by the COOKS DISTANCE TEST, indicating that the normal values and abnormal values were close to the distance and less than $20 \%$, which is recommended by the statistical world COOKS, which is estimated by the estimated model of $12 \%$ The data for the eighth stage is stable, while most of the stages were different in the data and the estimated distance by the test is more than $20 \%$. Therefore, this model is considered the best of the models and therefore it will be chosen to represent the relation between the ratio of change in GDP and investment.
\end{abstract}

Keywords: Economics, Energy Economics, Econometrics 


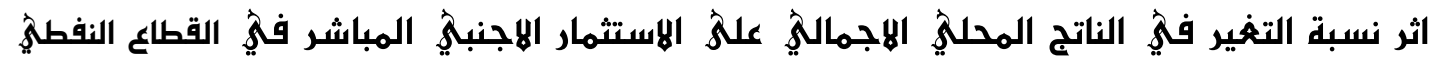

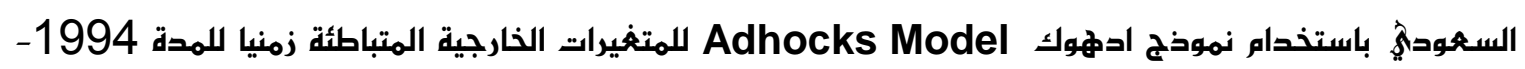

\author{
2017 \\ محمد راضي جعفر السوداني \\ كلية الادارة والاقتصاد - جامعة ميسان \\ عدنان داود محمد العذارى \\ كلية الادرة والاقتصاد -جامعة الكوفة
}

\begin{abstract}
الخلاصة

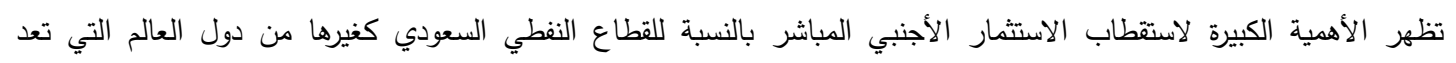

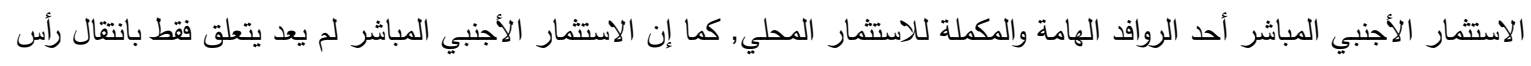

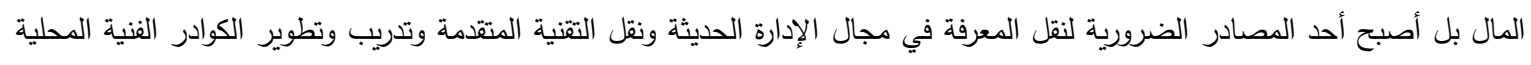

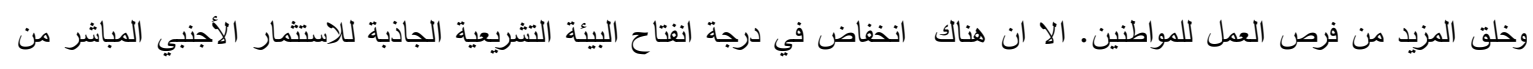

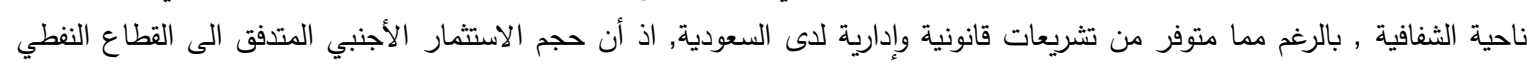

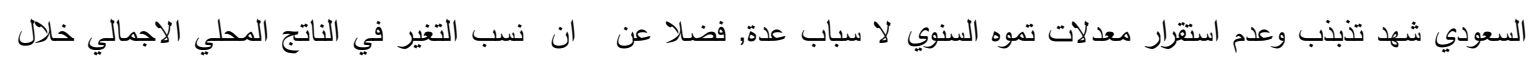

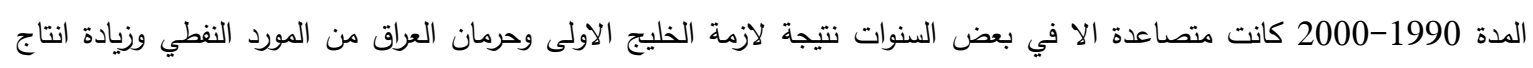

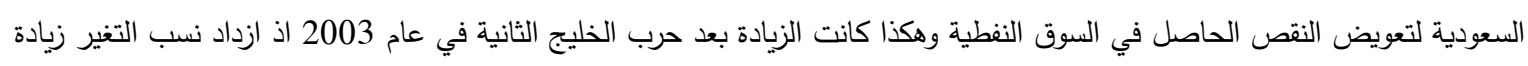

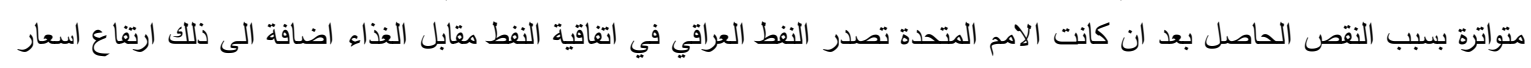

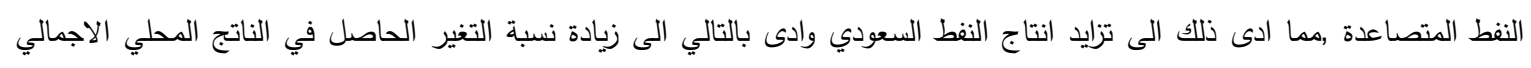
فضلا عن انه في النموذج المقدر في المرحلة الثامنة من جدول 3 تم اختبار بياناته باختبار

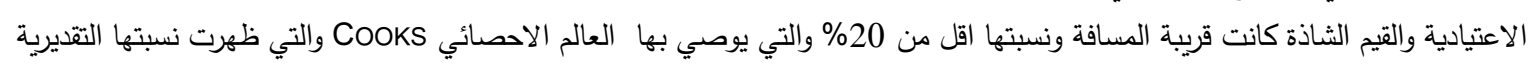

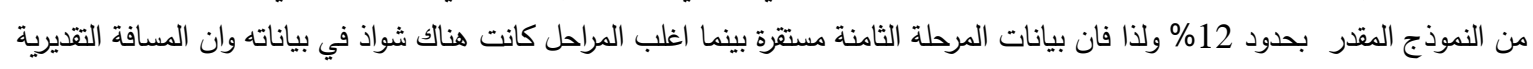

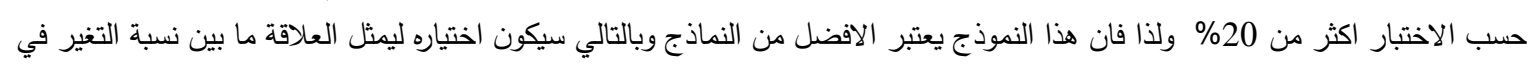
الناتج المحلي الاجمالي والاستثمار .

الكلمات الدالة: الاقتصاد, اقتصاد الطاقة , الاقتصاد القياسي

المقدمة

يعد الاستثمار الأجنبي المباشر احد أهم روافد رؤوس الأموال الدولية, نظرا للدور الحيوي الذي يشغله في رفع القدرات الإنتاجية للاقتصاد وزيادة معدلات التشغيل ,فضلا عن إدخال التقنية الحديثة. وان نمو الاستثمارات الأجنبية

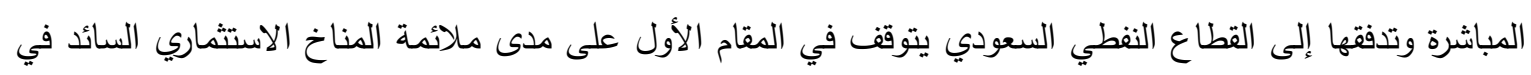

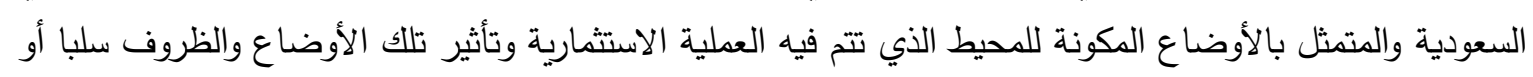
إيجابا على فرص ونجاح المشروعات الاستثمارية.

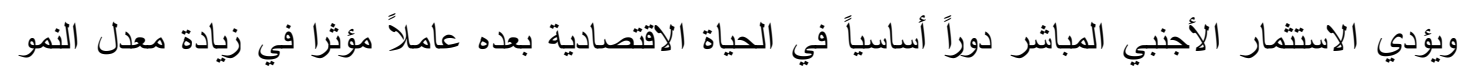

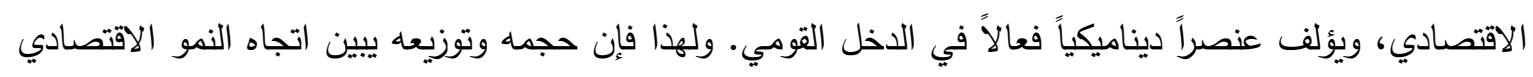

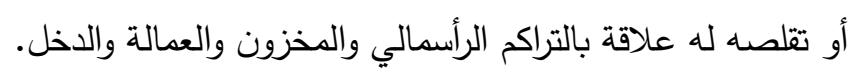


إن أهمية الاستثمارات الأجنبية المباشرة تكمن في الدور الذي تمارسه على النمو والتتمية في الدول المضيفة كما

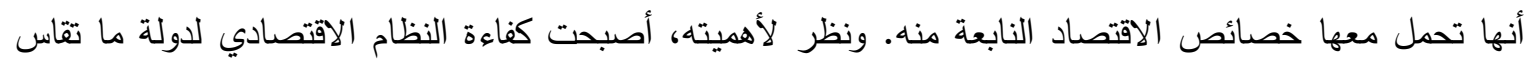

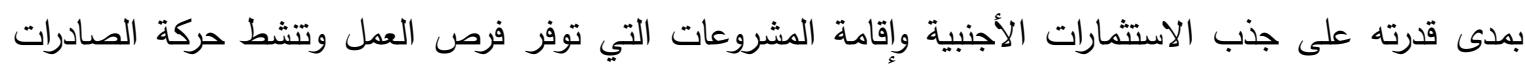
فضلا عن تحديث الصناعة الوطنية والوصول بها إلى مرحلة الجودة الثاملة والاستقرار السياسي في أي دولة مضيفه للاستثار , إذ يعد من أهم مكونات المناخ الاستثاري، فالاستقرار السياسي يولد الاستقرار الأمني وبالتالي

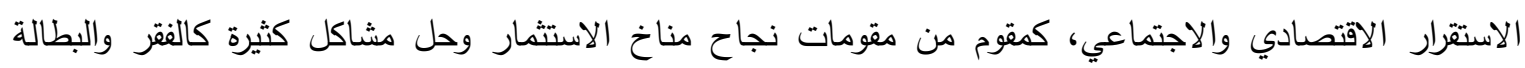
والتضخم وتوطين رؤوس الأموال الدحلية للاستثمار في الداخل...... الخ. أهمية البحث يعد الاستثمار الأجنبي المباشر مصدراً لتعويض العجز في الادخار المحلي وتحقيق زيادة في معدلات نمو الهو

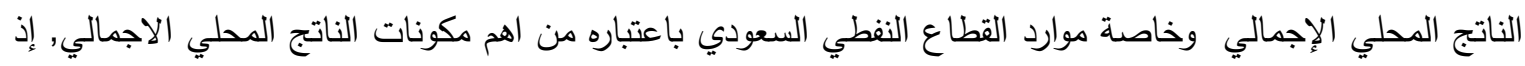

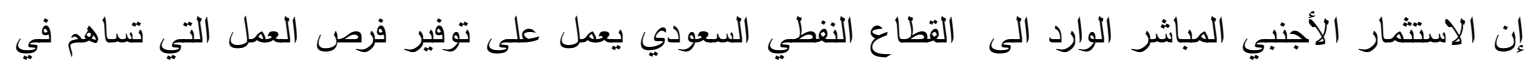
تخفيض مستويات البطالة ورفع مستوى الرفاه الاجتماعي ومواكبة العالم في ظل مفهوم الثركات متعددة الجنسيات

صاحبة الخبرة والتي تحمل في طياتها التكنولوجيا المتقدمة. مشكلة البحث

ان التغيرات التي تحصل في الناتج الهحلي الاجمالي السعودي هل يسبب تغيرا" في وضعية ودافع الاستثمار الاجنبي المباشر ؟ وهل انه يؤدي الى فاعاليته بصورة كبيرة مما ينعكس على النشاط الاقتصادي السعودي.

فرضية البحث

ينطلق البحث من فرضية مفادها(ان اي تغير في الناتج الدحلي الاجمالي يسبب تغيرا واضحا في فعالية

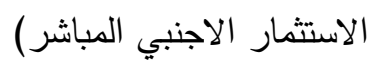
هل البحث

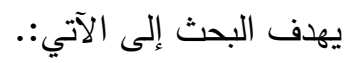
1-تعريف واستعراض مفهوم وإشكال الاستثمار الأجنبي المباشر الشي 2 - دراسة مدى ملائمة المناخ الاستثماري لجذب الاستثمارات الأجنبية وتطورها في السعودية 3- معرفة منافع الاستثمار الأجنبي المباشر الوارد إلى القطاع النفطي السعودي.

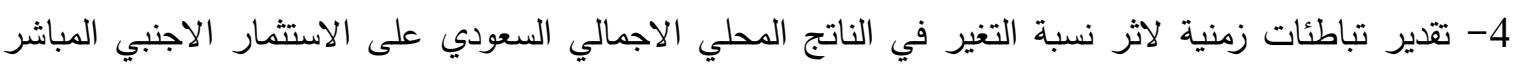

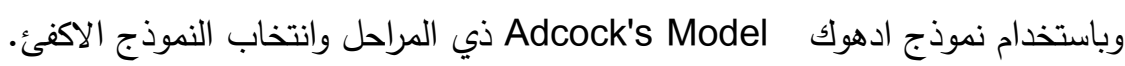

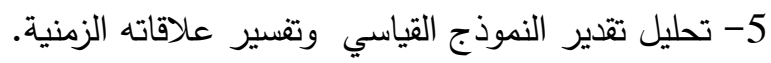
الاراسات السابقة

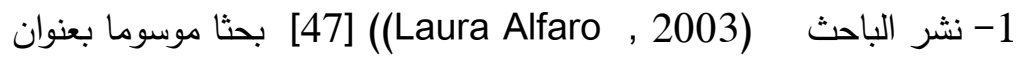
"Foreign Direct Investment and Growth0il : Does the Sector Matter" الاستثمار الأجنبي المباشر والنمو في القطاع النفطي: هل هذا القطاع , وقد كان يهدف الىى دراسة الاستثمار

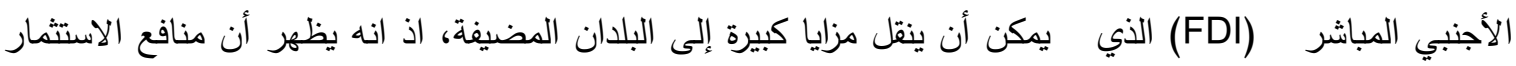

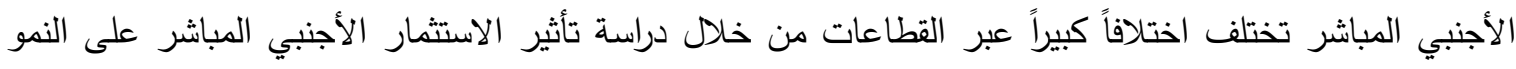
في القطاعين الأساسي والصناعي. وقطاعات الخدمات. ويشير تحليل تجريبي باستخدام البيانات عبر البلد للددة 
(1981-1999) إلى أن الاستثارات الأجنبية المباشرة في القطاع الأولي تميل إلى أن يكون لها تأثير سلبي على

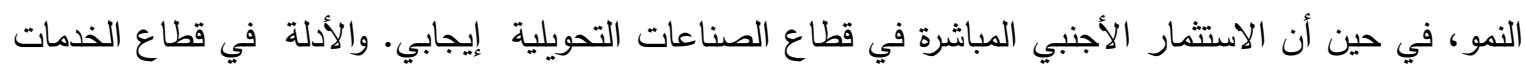
غامضة. 2- نشر الباحث (Mark J.KaiserAllan G.Pulsipher 2006) عثنا موسوما بعنوان "A review of the oil and gas sector in Kazakhstan" استعراض لقطاع النفط والغاز في كازاخستان وقد كان يهدف الى دراسة الموارد النفطية والغازية الكبيرة التي تتمتع بها كازاخستان، اذ من المتوقع أن تصبح واحدة من أكبر عشر دول منتجة للنفط في العالم خلال العقد القادم. اذ تقوم

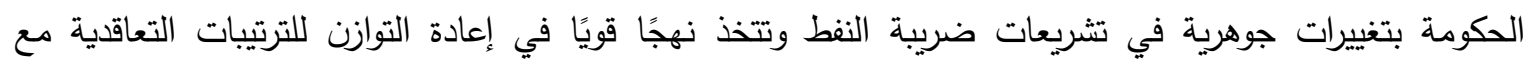

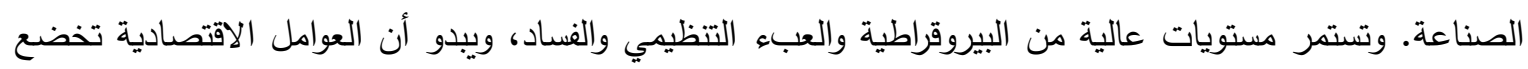

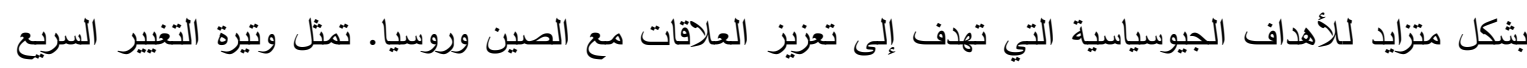
وارتفاع درجة عدم اليقين تحديات كبيرة ومخاطر على الاستثمار الأجنبي. الغرض من هذه الدراسة هو استعراض فئس

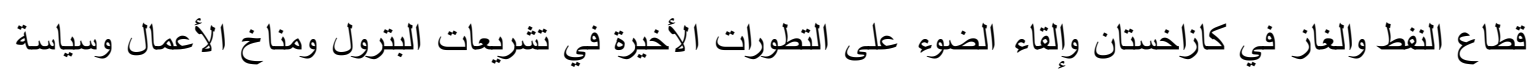

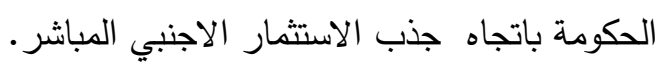

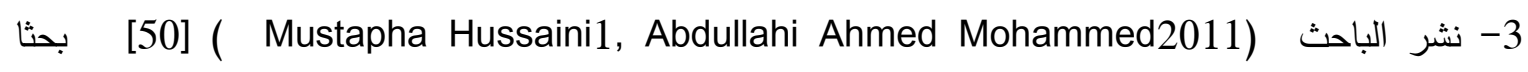
"Oil and Non-Oil Foreign Direct Investment and Economic Growth in بعوسوا بعنوان Nigeria: An Empirical Evidence from Autoregressive Distributed Lag Model"

الاستثمار الأجنبي المباشر والنمو الاقتصادي في القطاع النفطي والقطاع غير النفطي النيجيري ادلة

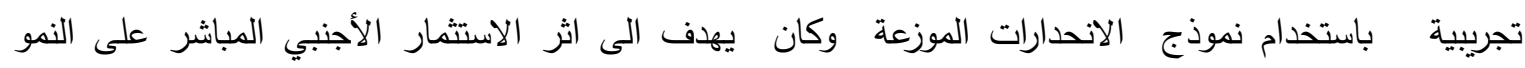

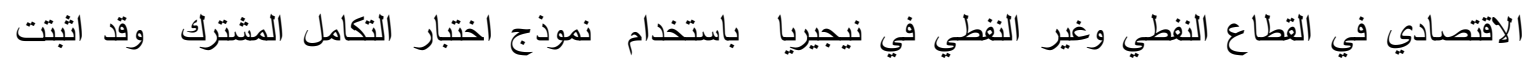

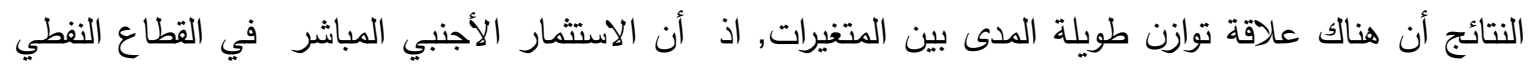

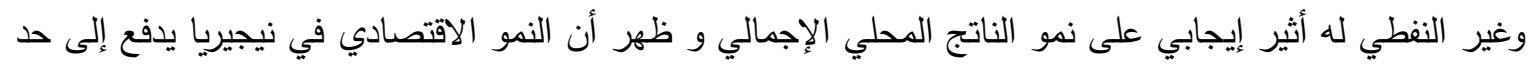

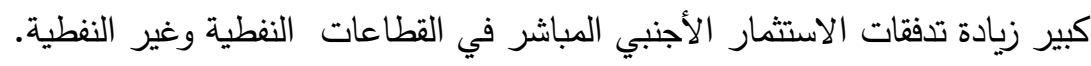

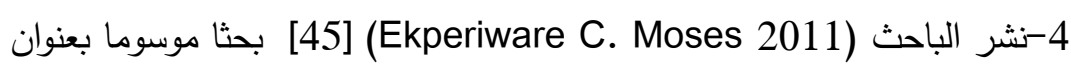

"Oil and Nonoil FDI and Economic Growth in Nigeria"

الاستثمار الأجنبي المباشر النفطي والاستثمار الأجنبي المباشر غير النفطي والنمو الاقتصادي في نيجيريا

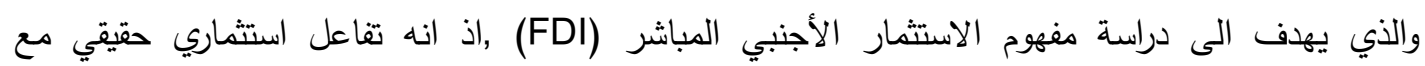

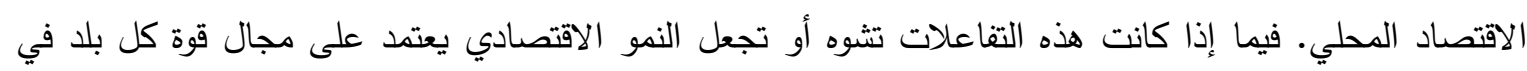
كيفية الاتجاه النسبي المتزايد للاستثار الأجنبي المباشر في الصناعة الاستخراجية لا سيما خلال الديمقراطية الحالية, اذ يطرح التوزيع مقارنة بالقطاعات غير الاستخراجية سؤالا إذا كان الكم يضيف بنفس الطريقة إلى النمو الاقتصادي في نيجريا.

اعتمد الباحث على تقنية OLS، باستخدام البيانات للددة (2008-1970) اذ يوضح أثر الاستثمار الأجنبي المباشر (OILFDI) في القطاع النفطي مقارنة بالقطاعات الأخرى على النمو الاقتصادي. النيجيري

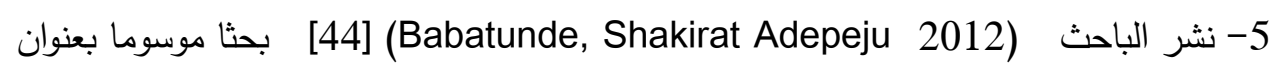
"The Impact of Tax Incentives on Foreign Direct Investment in the Oil and Gas Sector in 


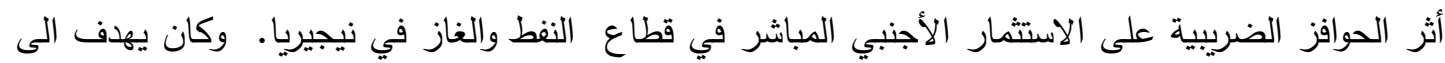

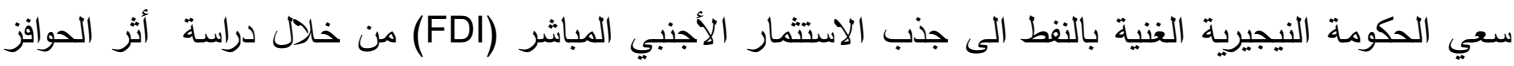
الضريبية على الاستثارات الأجنبية المباشرة في قطاع النفط والغاز ربسبب المزايا المعترف بها كأداة للتمية التئية الاقتصادية. ومع ذلك، فإن المفاضلة بين العوائد الضريبية والمكاسب المتوقعة من الاستثمار الأجنبي المباشر غير الشير متتاسقة هناك خلاف الأدلة في الأدبيات الاقتصادية.

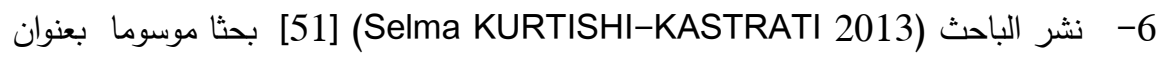

"The Effects of Foreign Direct Investments for Host Country's Economy" آثار الاستثمارات الأجنبية المباشرة على اقتصاد البلد المضيف وكان البحث يهذف الى دراسة آثار الاستثمارات الأجنبية المباشرة على اقتصاد البلد المضيف , اذ انه سلط الضوء على أهم القنوات التي تجعل من الاستثمار الأجنبي

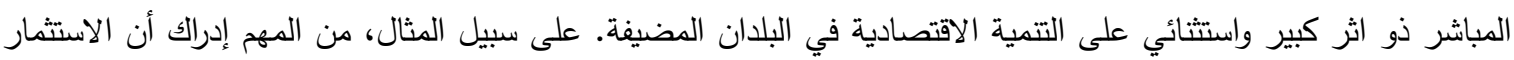

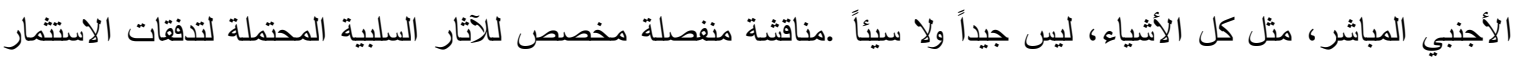

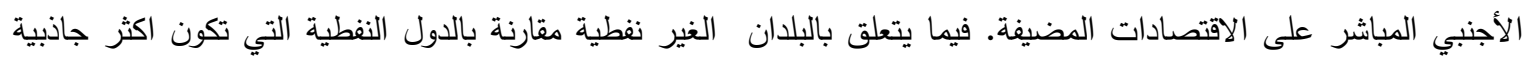

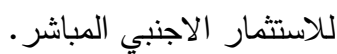

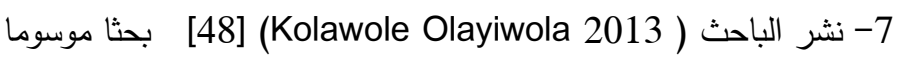
FOREIGN DIRECT INVESTMENT, NON-OIL EXPORTS, AND ECONOMIC" GROWTH IN NIGERIA: A CAUSALITY ANALYSIS1" الاستثمار الأجنبي المباشر، الصادرات غير النفطية، و النمو الاقتصادي في نيجيريا , تحليل قياسي وكان يهدف الى دراسة

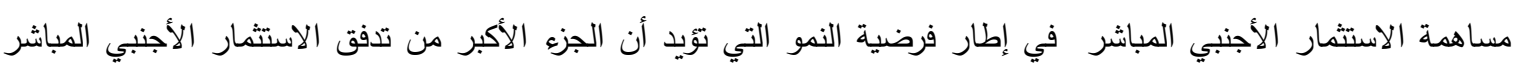

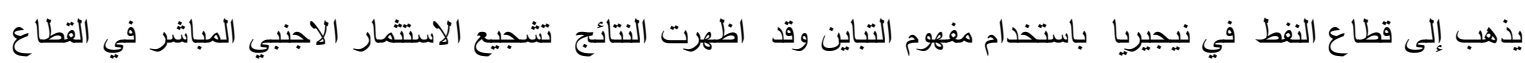
النفطي وغير النفطي في نيجريا

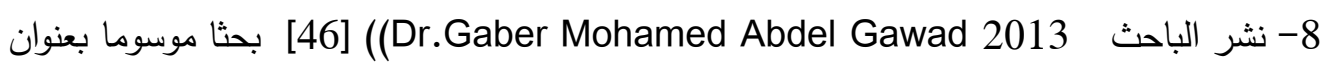
"Foreign Direct Investment (FDI) and Its Effects On Oil, G. as And Refinery

Production and Their Exports: An Applied Study" الاستثمار الأجنبي المباشر (FDI) وآثاره على النفط، G. إنتاج المصافي وصادراتها: دراسة تطبيقية وكان البحث يهدف الى العلاقة بين الاستثمار الأجنبي المباشر وصادرات النفط والغاز والمصافي في سبعة عشر بلدا مختارة من جميع دول العالم التي تجذب الاستثار الاجنبي المباشر ـ اليها خلال المدة (1995 - 2011) وباستخدام نموذج

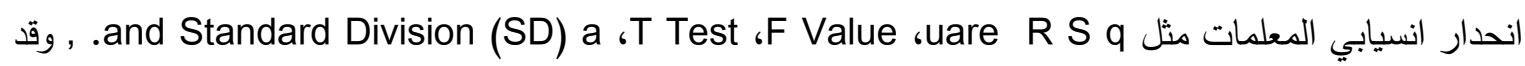
اظهرت النتائج المتفق عليها مع العديد من الدراسات. على اختلاف تدفق الاستثمار الاجنبي المباشر في القطاع

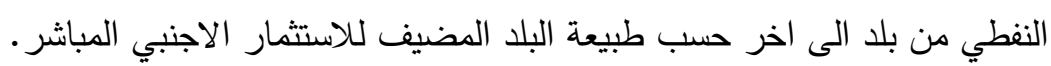

\section{المبحث الأول: الإطار ألمفاهيمي للاستثمار الأجنبي المباشر}

أولا: تعريف الاستثمار الأجنبي المباشر

يعرف الاستثمار الأجنبي المباشر بأنه نوع من أنواع الاستثمار العالمي الذي يعكس حصول كيان مقيم في

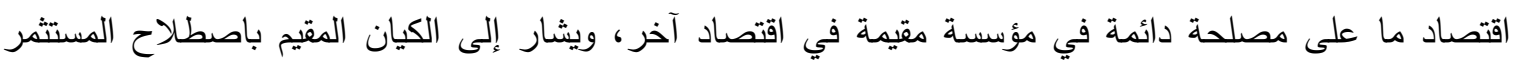
المباشر، وإلى المؤسسة باصطلاح مؤسسة الاستثمار المباشر ، وتتطوي المصلحة الدائمة على وجود علاقة طويلة 
الأجل بين المستثر المباشر والمؤسسة، فضلا عن تمتع المستثر بدرجة كبيرة من النفوذ في إدارة المؤسسة. ولأغراض هذا التعريف يكون الحد الفاصل لتعريف الاستثمار الأجنبي المباشر هو ملكية حصة في رأس مال الشركة التابعة في البلد المضيف تساوى أو تفوق 10\% من الأسهم العادية أو القوة التصويتية لمؤسسة الاستثمار

[19] المباشر ومن هذا التعريف يمكن أن نستتنج ما يلي: • • إن الاستثمار الأجنبي المباشر ينطوي على علاقة طويلة الأجل تعكس منفعة المستثر الأجنبي المباشر

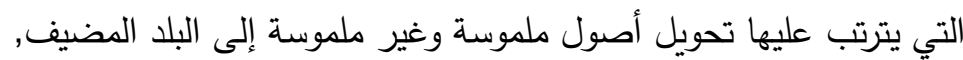
• • يكون للمستثر الأجنبي الحق في إدارة الوحدة التابعة والرقابة عليها.

وتجدر الاشارة الى ان الاستثار الاجنبي المباشر يشتمل على جانبين هما جانب مالي يمثل تدفق رؤوس

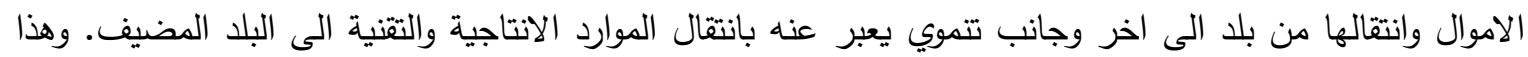

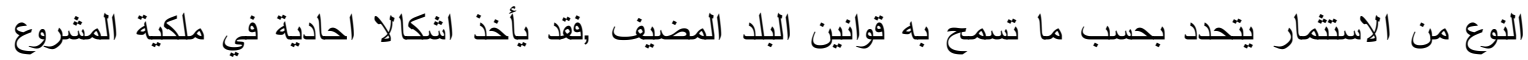

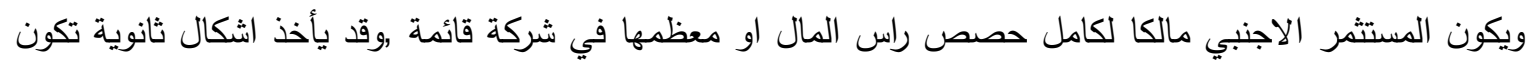
فيه ملكية المشروع موزعه بين راس المال الاجنبي وراس المال المحلي ,او يكون على شكل تدفقات الاستثمارات الاجنبية للشركات متعددة الجنسيات [18]

ثانيا :مفهوم الاستثمار الأجنبي المباشر يشهد العالم النامي الآن زيادة التنافس في سوق رأس المال الأجنبي، من خلال تقديم حوافز أفضل، وانشاء

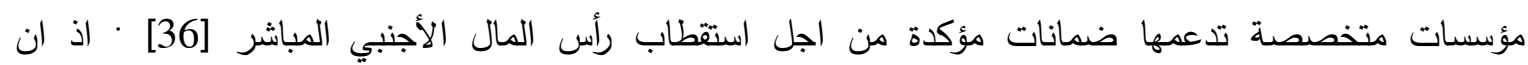

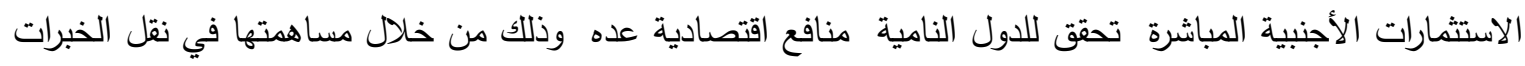

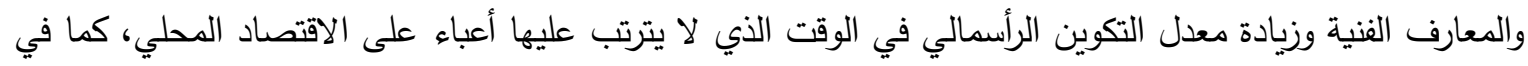

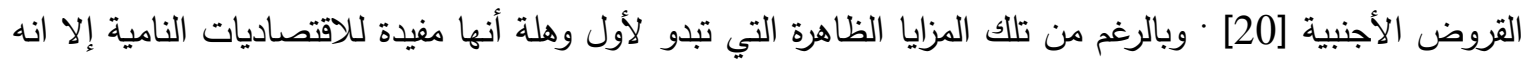

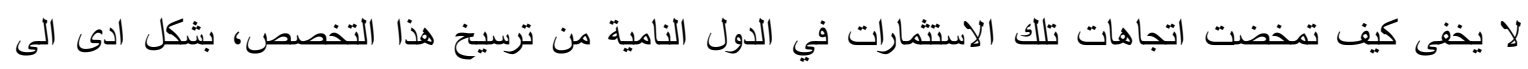

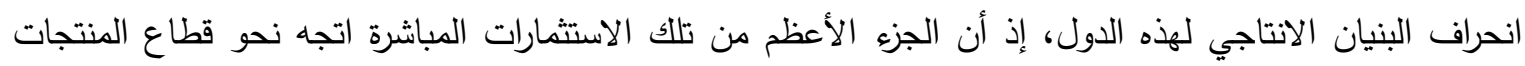

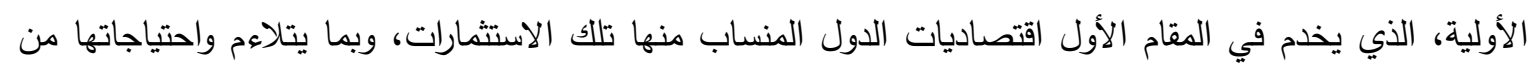

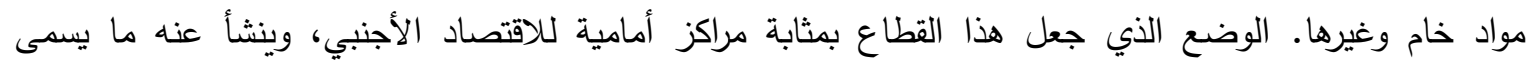

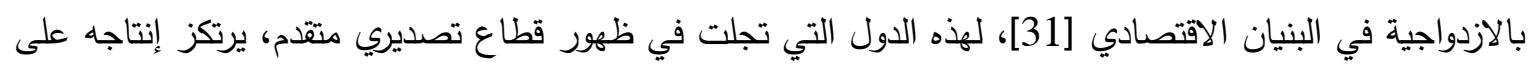

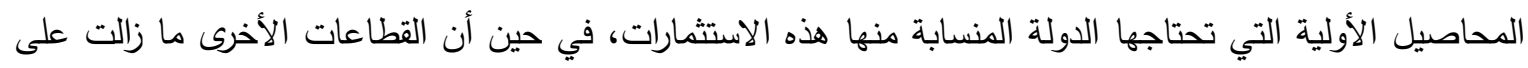

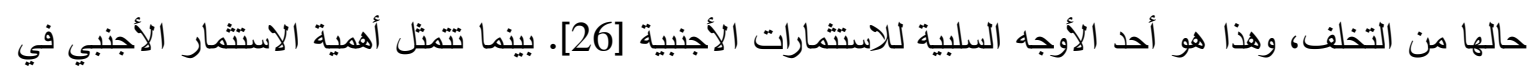

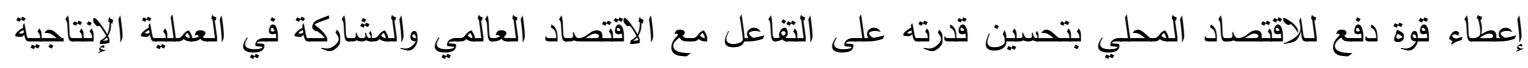

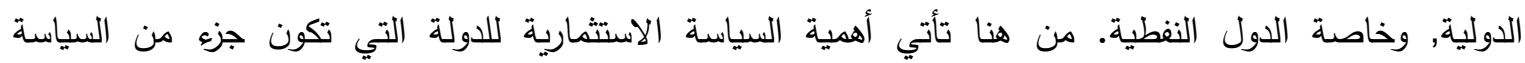
الاقتصادية الكلية وضمن استراتيجية التمويل الاقتصادي والالتحاق بركب الاقتصاد العالمي، وليس سياسة محدودة الأهداف متواضعة تتحصر في توفير الموارد المالية، على الرغم من أهميتها. 
ثالثا: أنواع الاستثمار الأجنبي المباشر يمكن تقسيم أنواع الاستثمار الأجنبي المباشر إلى أشكال مختلفة استتاداً الىى كيفية إنشاء المشروعات في البلد

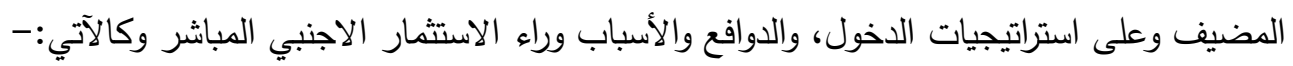

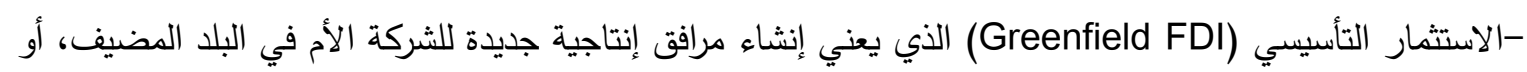
استثمارات عن طريق عمليات الاندماج والاستحواذ (Mergers and Acquisitions) الذي يعني قيام المستثر الأجنبي بشراء أو الاندماج مع شركة قائمة تعمل في البلد المضيف لإنشاء كيان قانئن الإني جديد. كما أن الاستثار

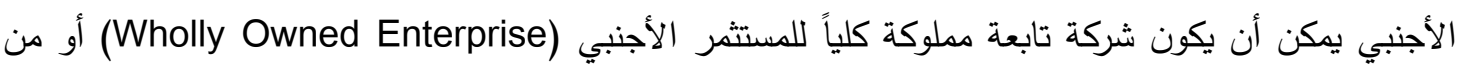

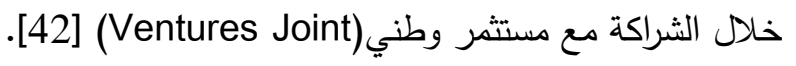
- الاستثمار الباحث عن الأسواق (Market Seeking ) الذي يهدف إلى خدمة السوق المحلي للدولة المضيفة

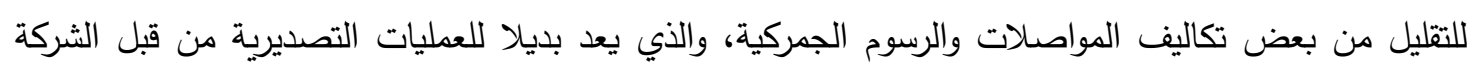

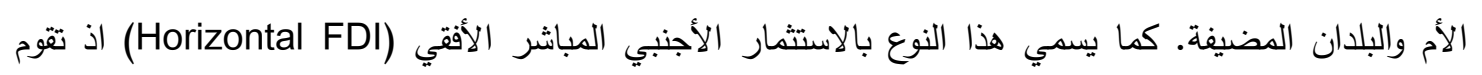
الشركة الأم بإنشاء وحدات إنتاجية تابعة في البلد المضيف لإنتاج نفس السلع والخدمات المنتجة التي تتنج في الإني

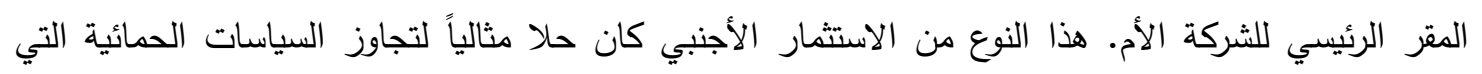
اتبعتها بعض الدول النامية في تطبيق سياسة إحلال الواردات خصوصاً دول أمريكا الجنوبية.

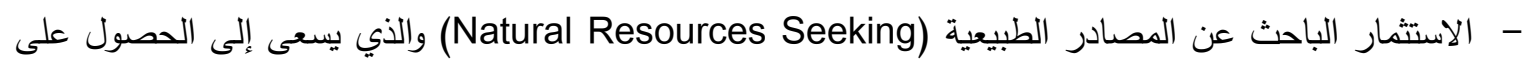
الموارد الطبيعية الرخيصة التي لا تتوفر في دولة الأم للشركة، من اجل استغلال الميزة النسبية للدولة المضيفة[13]. - الاستثمار الباحث عن الكفاءة (Efficiency Seeking) والذي تسعى الشركات الأجنبية من وراءه لزيادة كفاءتها

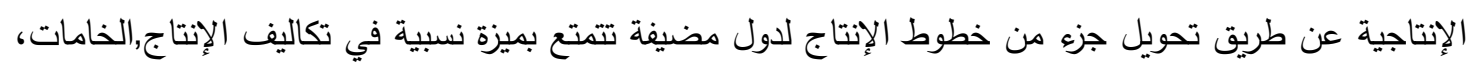

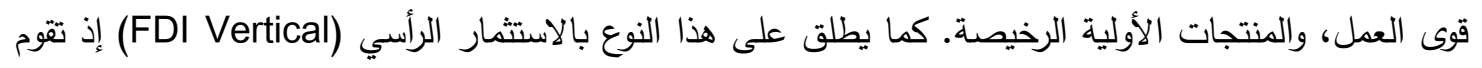
الشركة الأم بتوزيع خطوط أو مراحل عملية الإنتاج على دول مضيفة مختلفة. لذا يعد هذا النوع من الاستثمار

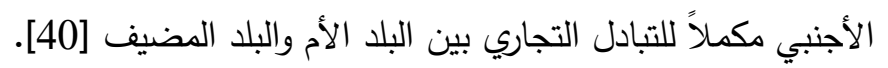
-الاستثمار الباحث عن أصول استراتيجية (Strategic Asset Seeking) والذي يسعى إلى الحصول على أصول

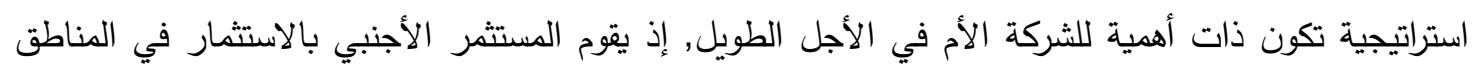

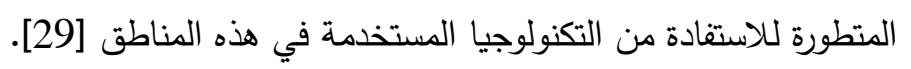
- الشركات المختلة: لقد تطورت الشركات المختلطة في السبعينات وذلك من خلال العلاقات الدولية بين الدول المتقدمة والدول

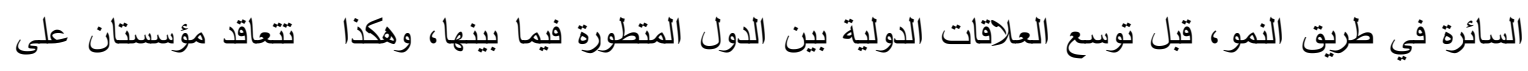

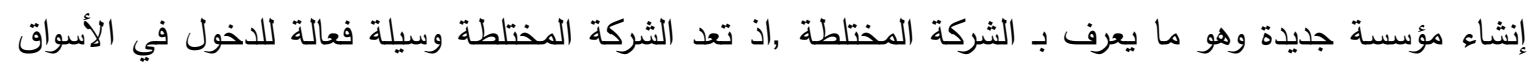
الدولية كونها تمثل تجمع التقنيات والخبرات. وعليه فان الدول الاشتراكية سابقا مثلا سمحت بشكل واحد من أشكال الاستثمار الأجنبي المباشر المتمثل في الشركات المختلة بمشاركة أجنبية لا تتعدى 49\%. و وتعد الشركات المختلطة في دول العالم الثالث وسيلة للمشاركة الواسعة للمستثر الأجنبي وتسيير المشاريع المراد انجازها فضلا عن تطوير الروابط الاقتصادية المختلفة [27]. 
- الاستثمار المموك بالكامل للمستثر الأجنبي (الشركات المتعددة الجنسيات) مشروعات الاستثمار المملوكة بالكامل للمستثر الأجنبي أكثر أنواع الاستثمارات الأجنبية تفضيلا لدى الثيات الشركات

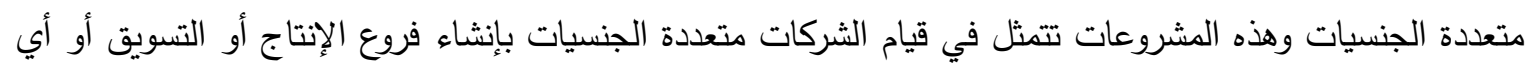

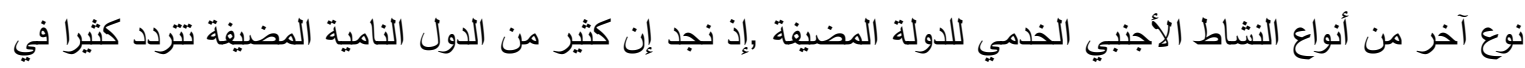

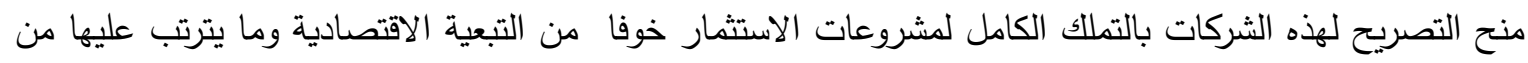

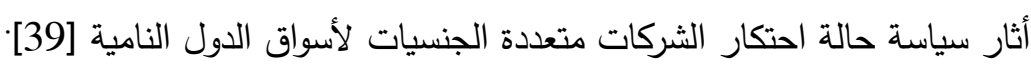

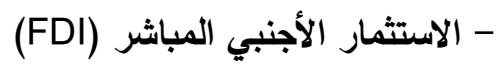

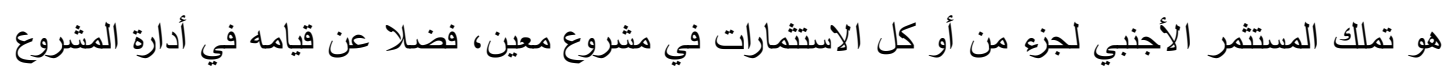
مع المستثر المحلي في حالة الاستثمار المشترك أو سيطرته الكاملة على الإدارة والتتظيم في حالة ملكيته المطلقة

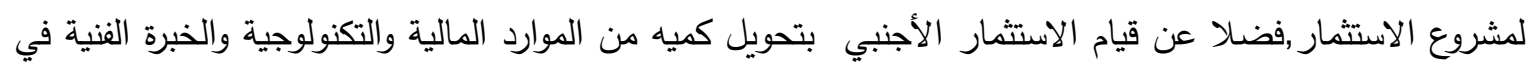
جميع المجالات إلى البلدان المضيفة(41].

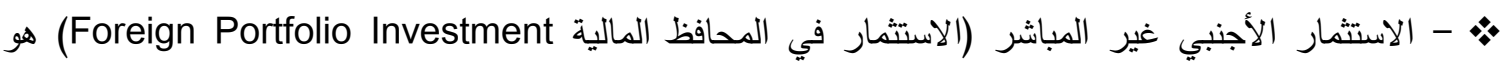
الاستثمار الذي ينطوي على تملك الأفراد أو الهيئات أو الشركات الأجنبية على الأوراق المالية , دون ممارسة أي نوع من الرقابة أو المشاركة في تتظيم وإدارة المشروع الاستثماري. ويعد الاستثمار في الأوراق المالية الستثماراً

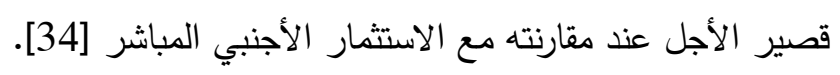

رابعا: قانون الاستثمار في السعودية صدرت قوانين لتثجيع الاستثمار الاجنبي المباشر في السعودية كان اولها في عام 1964 اذ كانت العمومية

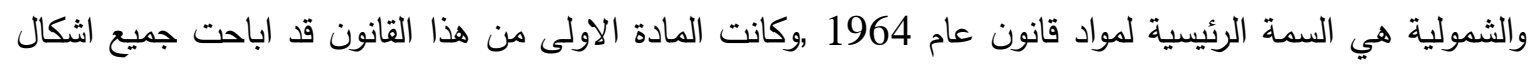
راس المال الأجنبي (النقود, عملات, اوراق مالية, الآلات ,المعدات, مواد الخام, المنتجات, وسائل النقات النقل والمواصلات

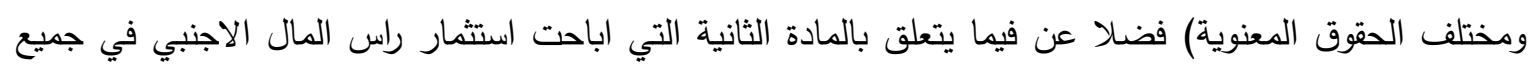
القطاعات الاقتصادية. وان المادة الثامنة نصت على الحوافز والمزايا التي يحصل عليها المستثر الاجنبي منها باتها الاعفاءات من الضرائب ,وخلال عام 1979 صدر قانون اخر لتشجيع الاستثمار الاجنبي المباشر يتعلق باعتماد

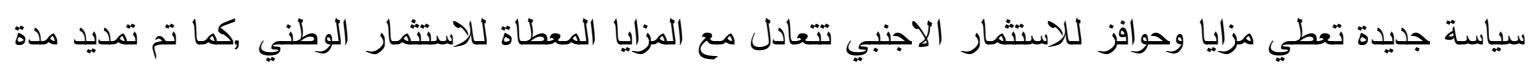

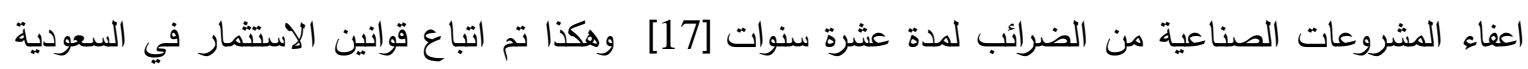
حتى الان.

\section{المبحث الثاني: شروط ومناخ الاستثمار الأجنبي المباشر في السعودية}

اولا:- شروط جذب الاستثمارات الأجنبية المباشرة في السعودية

يمكن ادراج اهم شروط جذب الاستثمار الاجنبي المباشر وكالآتي:

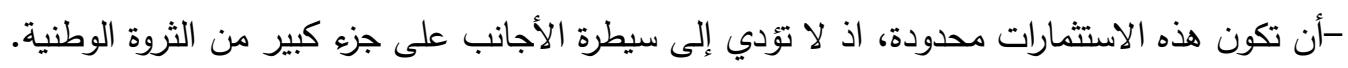

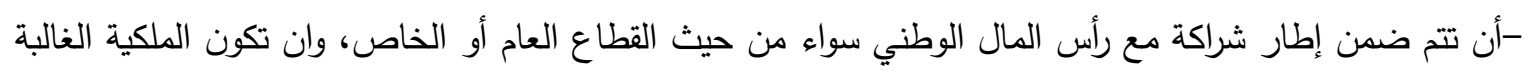
لرأس المال الوطني.

-أن توجه لإقامة مشاريع صناعية غير متوفرة في الدولة المضيفة. 
-وضع قواعد لتصفية الاستثمارات الأجنبية إذا رغب مالكوها بذلك، اذ لا يؤدي تحويل قيمها إلى حدوث ضغوط غير مناسبة على موازين مدفوعات الدولة المضيفة لها

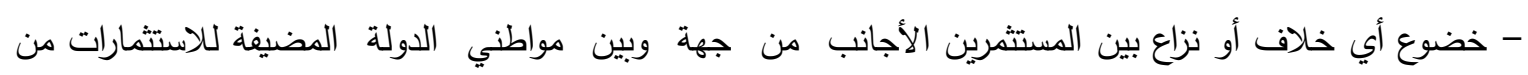
جهة أخرى إلى قوانين الدولة المضيفة

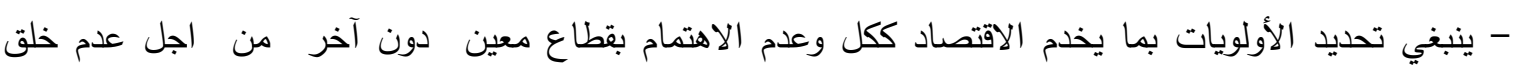

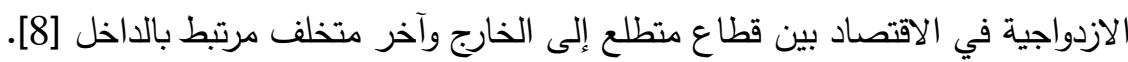

ثانيا: مناخ الاستثمار في السعودية قبل التطرق الى مناخ الاستثمار في السعودية لابد ان نطلع على مكونات المناخ الاستثماري في الدول المضيفة للاستثمار الاجنبي المباشر وكالاتي:ان الوضع السياسي للدول المضيفة للاستثمار ومدى ما تتسم به من استقرار ، بتظيماتها الإدارية، وما تتميز به من فاعلية وكفاءة، ونظامها القانوني ومدى وضوحه وثباته وتوازن ما ينطوي عليه من حقوق وأعباء، والسياسات

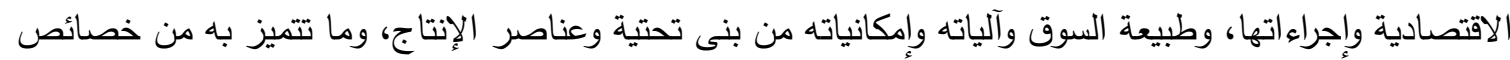
جغرافية، وديموغرافية على ذلك يشكل ما اصطلح على تسميته بمناخ الاستثمار (24). وعليه فان مناخ الاستثمار يعبر الإنيا

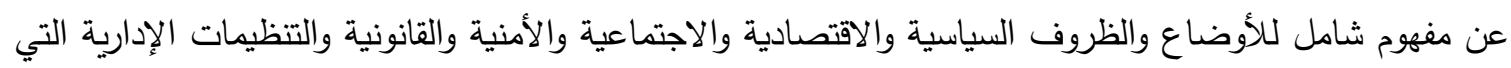
يمكن أن تكون ملائمة ومناسبة لجذب وتشجيع الاستثمارات المحلية والأجنبية.

ويمكن ذكر أهم مكونات المناخ الاستثماري بالثكل الاتي [15]:-

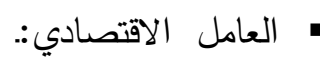

يتمثل هذا العامل بالبنية التحتية والأوضاع الاقتصادية السائدة في البلد وآفاق تطورها، إذ إن البنية التحتية

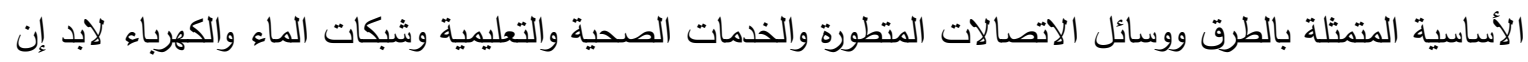
تلعب دورا مهما ومؤثرا ليس فقط في تحديد حجم الاستثمار المستقطب بل في كيفية توزيعها بين القطاعات

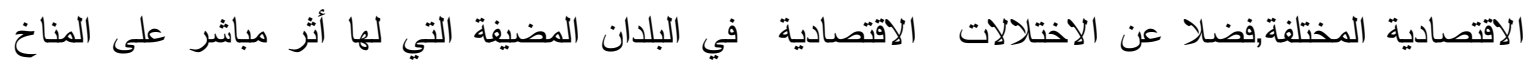
الاستثاري، خاصة فيما يتعلق بـ معدل التضخم، تقلبات سعر الصرف، مدى تطور الجهاز المصرفي، حجم السوق

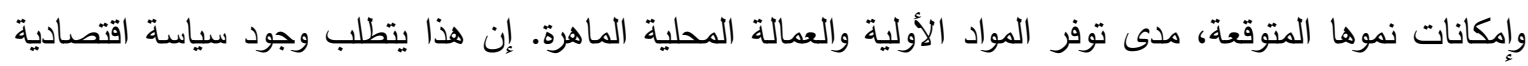

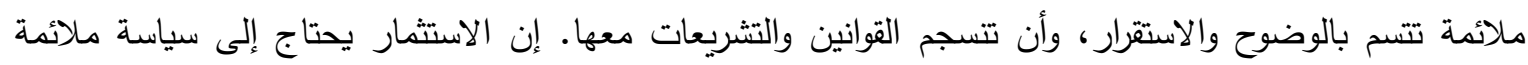
تعطي الحرية، ضمن إطار الأهداف العامة للقطاع الخاص في الاستيراد والتصدير وتحويل الأموال والتوسع في

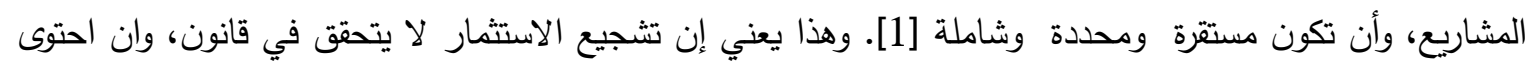

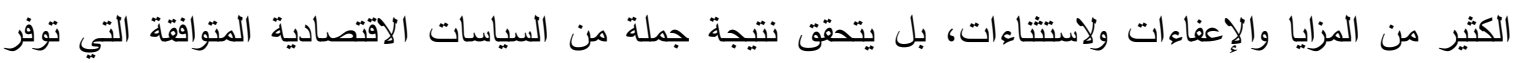

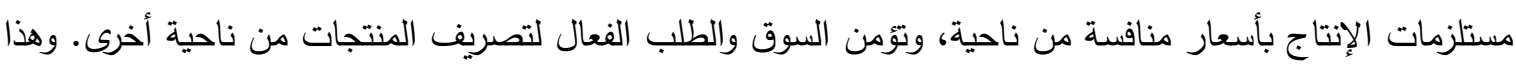

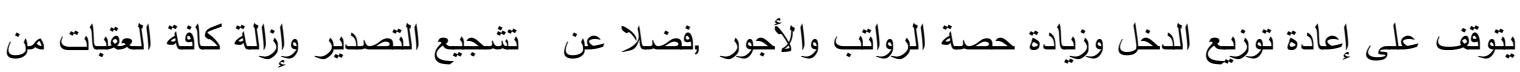
أمامه. • العامل السياسي (ماءل يعد العامل السياسي واحد من أهم العوامل في اتخاذ مختلف القرارات الاستثمارية الخاصة، فالمستثمرون

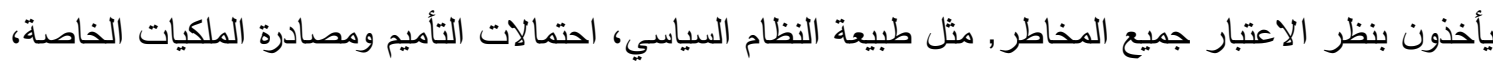

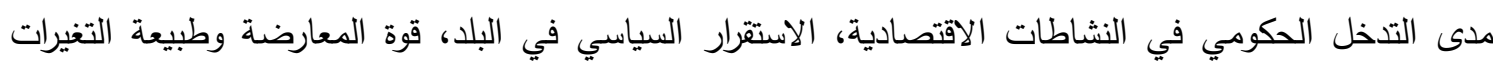


السياسية المحتملة، وغير ذلك من الأوضاع والظروف السياسية والاجتماعية في البلد المضيف.إذ إن عدم الاستقرار

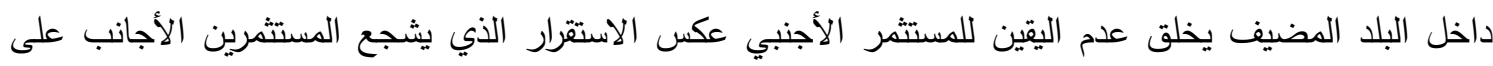

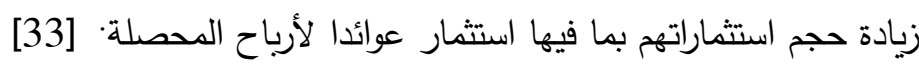

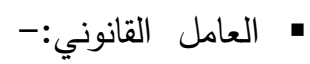

إن وجود الإطار القانوني يؤدي إلى إرساء الأسس التشريعية والقانونية المنظمة للنشاط الاقتصادي عامة

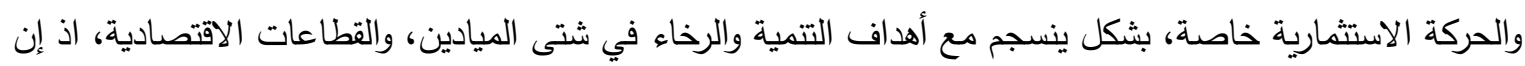

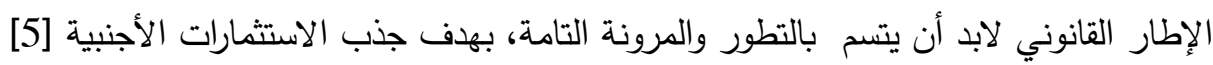
• • ب التكيف الحكومي:-

يؤدي التكيف الحكومي إلى زيادة الاستثمار الأجنبي المباشر كونه يقلص من عدم الاستقرار الاقتصادي , السياسي, القانوني والإداري, وبالتالي يقلص من درجة الخطر [19]. ويتم قياس التكيف الحكومي بالمتغيرات التالية

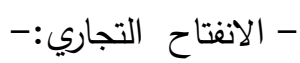
الانفتاح التجاري هو حرية الأسواق, أي إن هناك تدخل ض ضعيف للدولة في الأسواق ،وأن نظام التصدير والاستيراد مفتوح ,لذا فان زيادة الانفتاح التجاري يساهم في زيادة النان تدفق الاستثمار الأجنبي المباشر [21].

- النزاهة والثفافية القانونية والإدارية

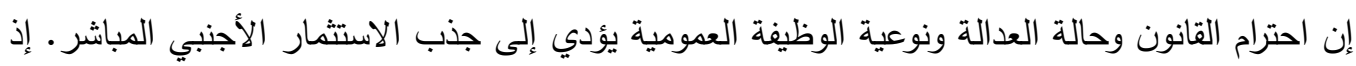

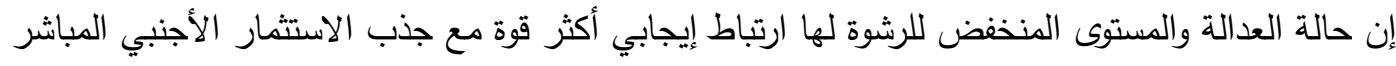

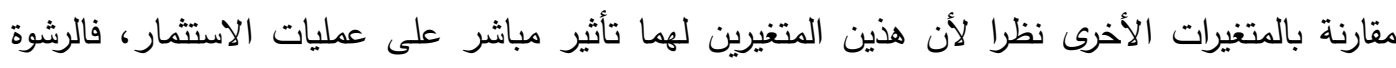

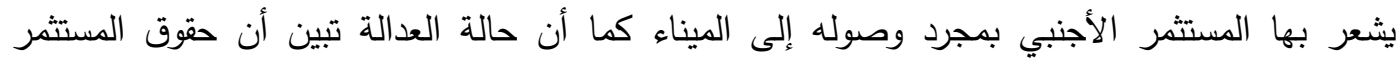

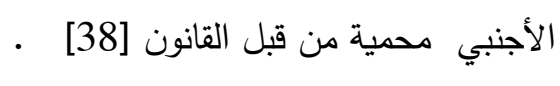

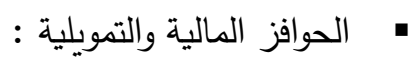

الحوافز المالية هي الحوافز التي تتعلق بالتخفيضات والإعفاءات الضريبية والجمركية المختلفة خلال مدة محدودة, قصيرة رمتوسطة , طويلة , تتفاوت حسب القطاع الذي توجه له الاستثمارات, وفي جميع الأحوال تتراوح مدة الإعفاء الكامل من 3- 20 سنة ويستمر الإعفاء خلال مدة وجود الاستثمار .

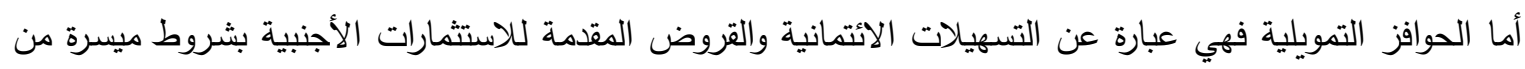
خلال توفير الأموال مباشرة للمشروع على شكل إعانات كوبية أو قروض بفوائد مخفضة. أن الدول النامية تجد

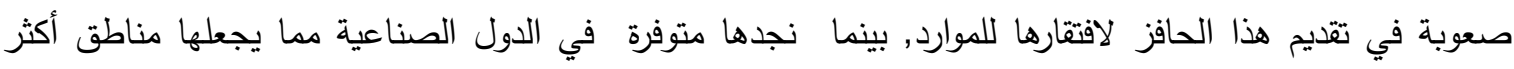

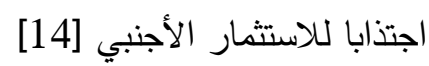

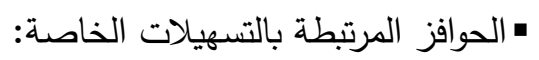
تعد هذه الحوافز في مجملها من الحوافز التمييزية التي تشمل بالتهلته الآتي: -عدم وضع أي قيود على تملك المشروعات الاستثارية سواء كان تملك كاملا أو جزئيا والسماح للمستثرين الأجانب بتملك الأراضي والعقارات. - تخفيض الرسوم الخاصة باستخدام واستغلال المرافق العامة كالمياه، الكهرباء وتخفيض قيمة الإيجار العقاري والأراضي الخاصة بالمشروعات الاستثمارية [25]. 
وعليه وبعد ان اصبحت لدينا مكونات المناخ الاستثماري واضحه اصبح لزاما علينا تلخيص اهم النقاط المتعلقة بمناخ الاستثمار في السعودية وكالاتي [22]: انخفاض درجة انفتاح البيئة التشريعية الجاذبة للاستثمار الأجنبي المباشر من ناحية الشفافية ربالرغم من

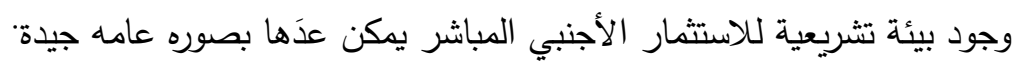

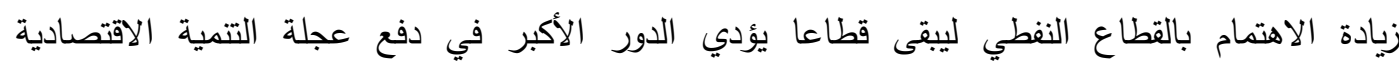
والاجتماعية وتتمية قطاع الصناعات المرتبطة به بوبالتالي محدودية جهود تتويع مصادر الدخل لتحفيز

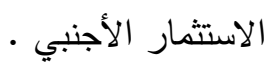
تعاني التشريعات المحلية المتعلقة بالاستثمار الأجنبي المباشر من صعوبات رسواء من حيث التسهيلات المقدمة للمستثر الأجنبي أو درجة الشفافية .

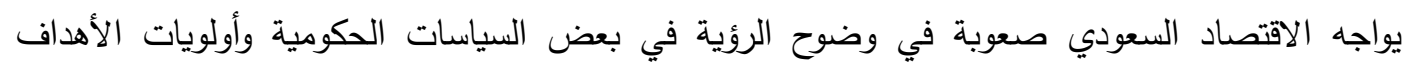

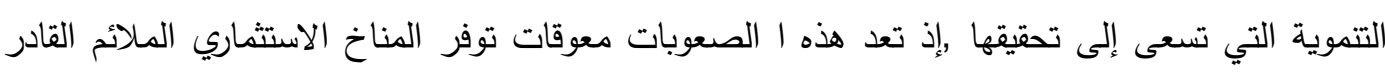

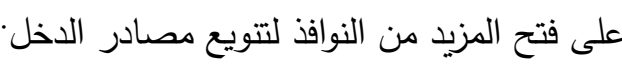
استمرار سيطرة القطاع العام والدور الكبير للحكومة في الحياة الاقتصادية، إذ إن ذلك يؤدي إلى تقليل الاعتماد على القطاع الخاص في دفع عملية التتمية الاقتصادية، وفلك الاختتاق في المشاريع التي تحتاج

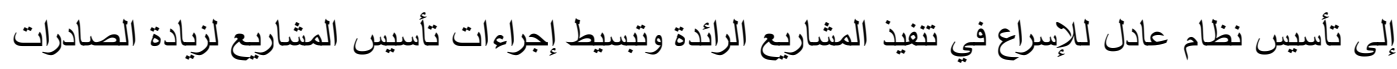

$$
\text { وتتويع مصادر الدخل وجذب الاستثمارات[28]. }
$$

ضعف درجة مشاركة القطاع الخاص في الناتج المحلي الإجمالي وفي تتمية الصادرات بالرغم مما يملكه من إمكانيات وقدرات على تعبئة مدخراته ومرونة وسرعة الاستجابة لمتطلبات التتمية والاستثمار، وهذا فئات

$$
\text { يضعف من جهود جذب الاستثمارات. }
$$

بط ء الإجراءات في إصدار تراخيص إقامة بعض المشاريع الاستثمارية. ارتفاع أسعار إيجار الأراضي، خصوصاً في المناطق الصناعية، وسيطرة الحكومة على أسواق الأراضي

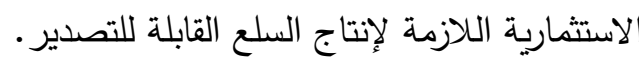
ضعف مستوى الخدمات الضرورية المتعلقة بتوفير البيانات والمعلومات التي تساعد المستثر على سرعة لإنتانية اتخاذ القرار . صعوبات هيكلية تتعلق بسوق العمل ووجود قطاع عام كبير قد لا يتصف بالكفاءة، وضعف في الإنتاجية.

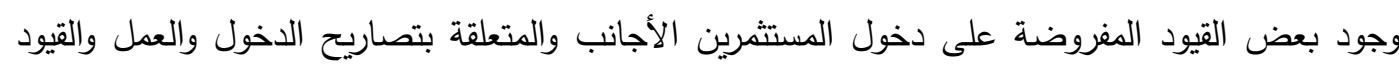

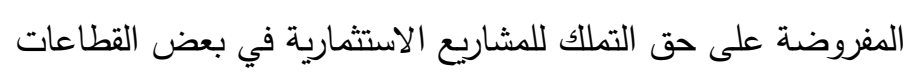
معوقات تتعلق بالبنوك المحلية وضرورة الحاجة إلى مراجعة سياساتها ونوعية الخدمات التي تقدمها، ولا

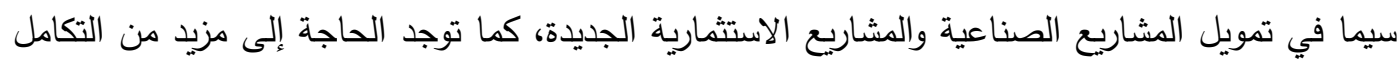
بين أسواق رأس المال الخليجية

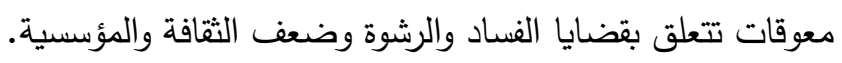

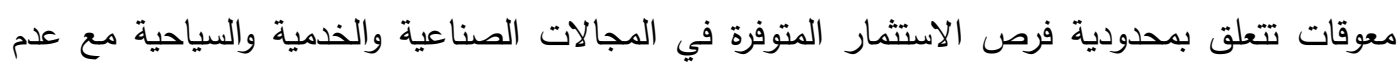
وجود دراسات جدوى اقتصادية جاهزة لهذه المشاريع [6]. رأس المال جبان, عبارة تتكرر على ألسن رجال الأعمال والاقتصاديين بصورة مستمرة، تدفع الدول المضيفة

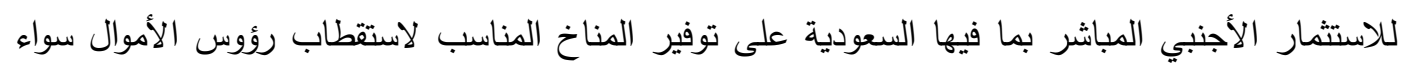


المحلية منها أو الأجنبية للمساهمة في تعزيز اقتصاديات هذه الدول[8].. ولكن يبدو أن الدول عادة ما تركز

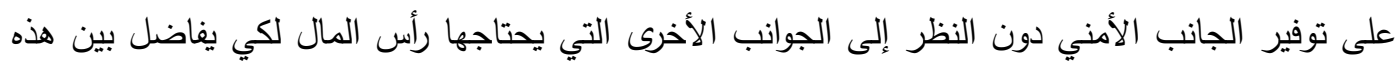
البيئة أو تللك [32] تُوفئ. يتضح من خلال النقاط الموضحة أعلاه بان المناخ الاستثماري في السعودية لم يعد ملائم مع زيادة تدفقات

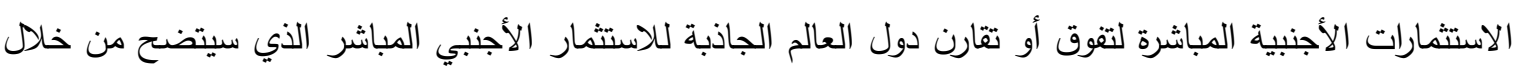
المبحث الثالث تطور الاستثمار الأجنبي المباشر .

المبحث الثالث: مزايا وتطور الاستثمار الأجنبي المباشر الوارد الى القطاع النفطي السعودي أولا: مزايا الاستثمار الأجنبي المباشر مرابر هناك مزايا عدة للاستثمار الأجنبي المباشر تكون ذات الهمية الأية على الاقتصاد السعودي هي كالآتي: - دور الاستثمار الأجنبي المباشر في ميزان المدفوعات:-

إن دور الاستثمار الأجنبي المباشر في ميزان المدفوعات السعودي يتحقق من خلال ارتباط حساب رأس المال

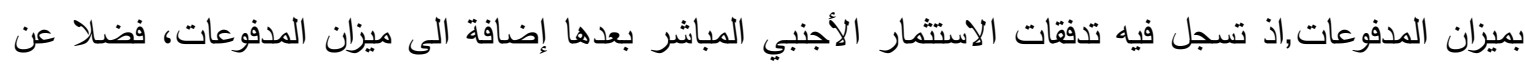

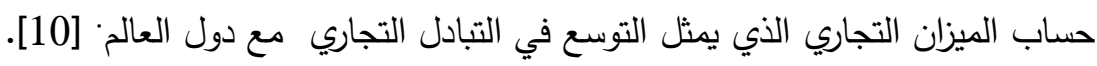

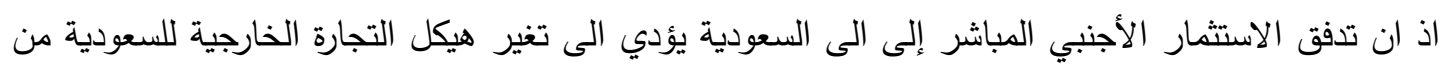

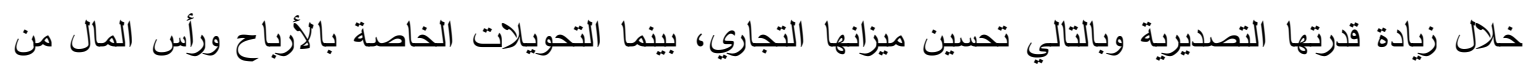
السعودية نحو الخارج تؤثر سلبا على ميزان المدفوعات. كذلك الاستثمار الباحث عن الأسواق يؤثر بشكل سلبي على الميزان التجاري خصوصاً إذا كانت الثركة الأجنبية الراعية للاستثمار الاجنبي المباشر في السعودية تستورد مدخلات الإنتاج كالمواد الخام والمنتجات الوسيطة

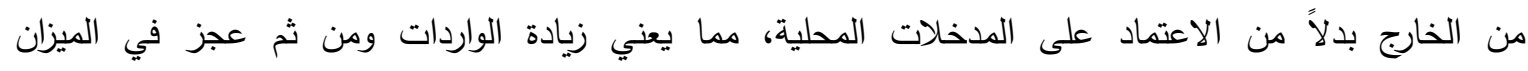

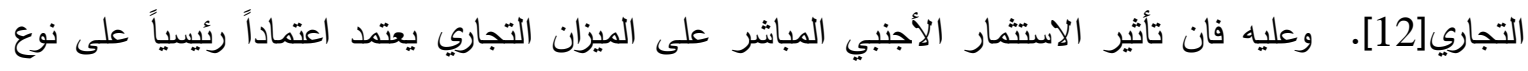

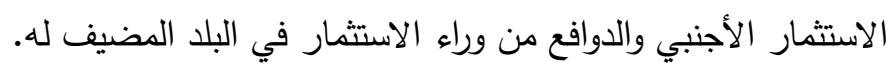

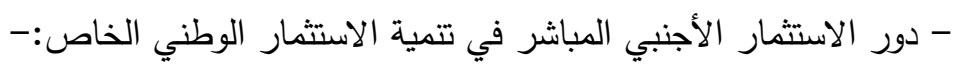

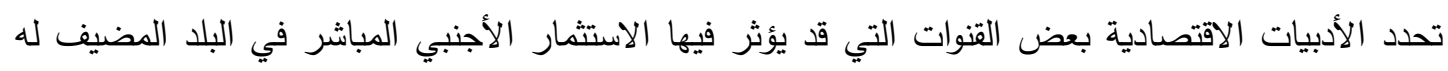
(السعودية) على نظيرة الوطني الخاص. بعض هذه التأثيرات ايجابية تؤدي إلى زيادة معدل الاستثمار الوطني الإني الخاص, وبعضها سالبة تؤدي إلى انخفاض الاستثمار الوطني. لوني.

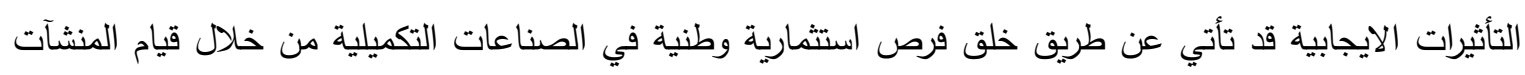

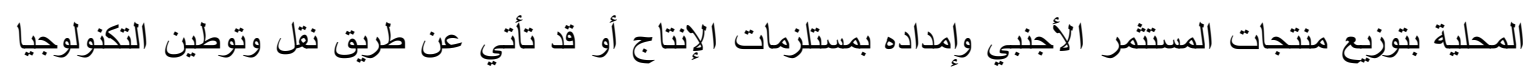
التي تؤثر على مدى كفاءة المنشآت المحلية في استخدام عناصر الإنتاج الذي يساعدها على تقليل تكاليف الإنتاج

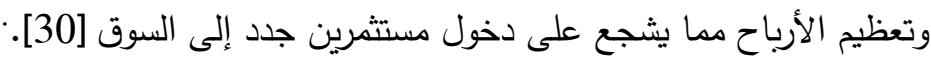

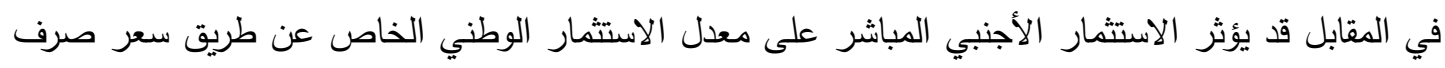

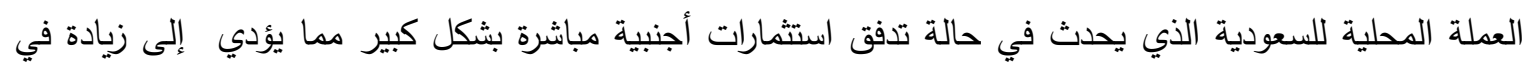
سعر صرف العملة الريال والذي يؤثر سلباً على القدرة التتافسية للمنشآت المحلية في تصدير منتجاتها إلى الأسواق

فضلا عن تأثير هذه الاستثمارات على الكيفية التي يدخل فيها الاستثمار الأجنبي إلى السعودية [35]. 
- دور الاستثمار الأجنبي المباشر في سوق العمل:من المعروف ان دور الاستثمار الأجنبي المباشر في سوق العمل يؤدي الى خلق فرص فرص عمل جديدة، وزيادة

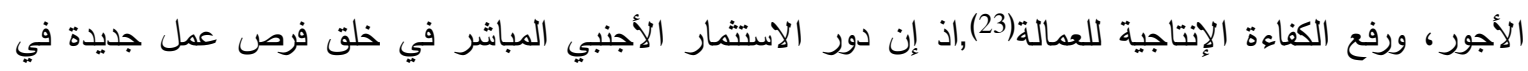

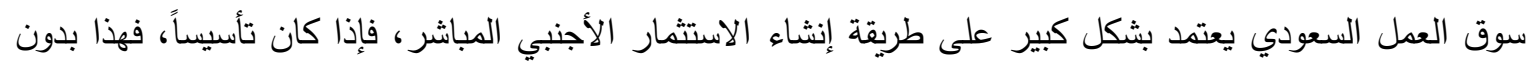

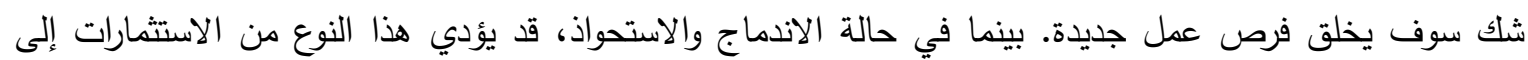

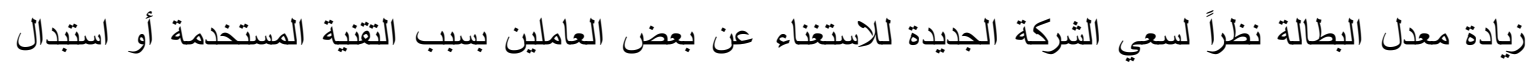

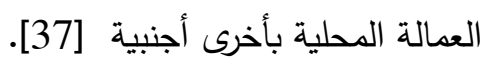
- دور الاستثمار الأجنبي المباشر في النمو الاقتصادي للسعودية:-

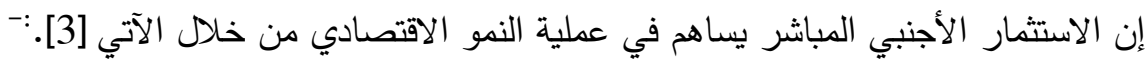

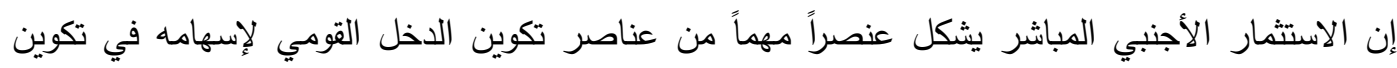
رأس المال الثابت. يقدم المعرفة التقنية المطلوبة التي تساعد على زيادة الكفاءة الإنتاجية للصناعات التي يعمل فيها المستثر الأجنبي. يؤدي الاستثمار الأجنبي المباشر دوره في النمو الاقتصادي السعودي من خلال دوره الايجابي في تحسين

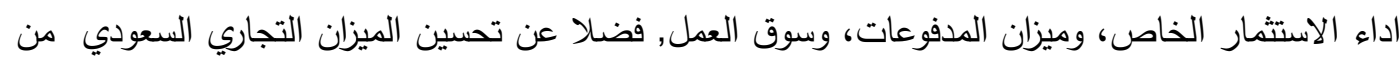

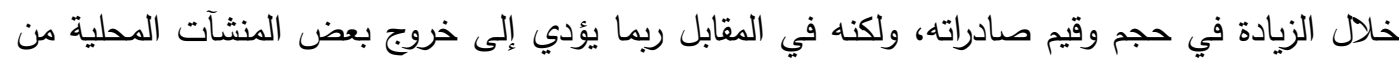

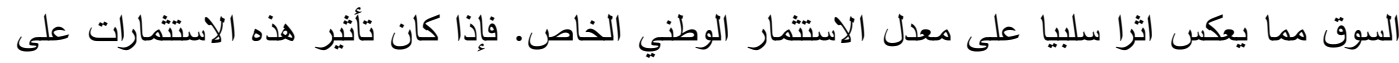

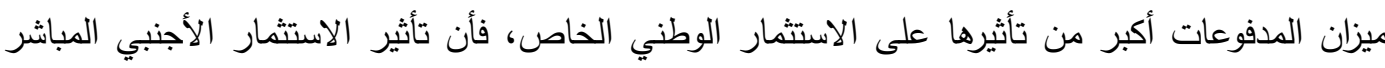
سيكون موجباً والعكس صحيح. أن دور الاستثمار الأجنبي المباشر على اقتصاد السعودية يعتمد على التفاعل الديناميكي لمجموعة من

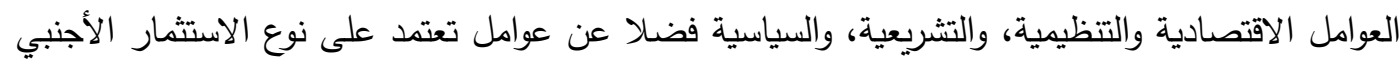

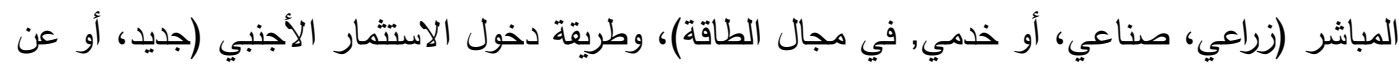
طريق الاندماج أو الاستحواذ)، وسياسات الدولة المضيفة اتجاه هذه الاستثمارات، وبيئتها الاستثمارية.

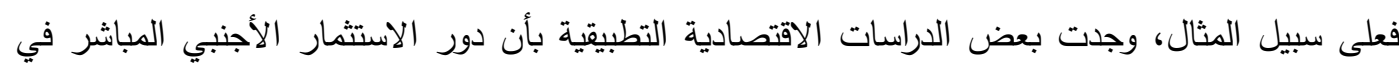
النمو الاقتصادي للبلد المضيف يعتمد على جودة رأس المال البشري Human) Capita)الذي تمتلكه الدولة. بينما وجدت بعض الدراسات أن هذا الدور يعتمد أيضاً على درجة تطور ونمو القطاع المالي والمصرفي في البلد المضيف، كذلك وجدت بعض الدراسات أن الدول التي تتتهج سياسة الاقتصاد المفتوح تتنفع من الاستثمار الأجنبي أكثر من تلك التي تتبع السياسات الحمائية [4].

وعليه فانه لا يمكن تجاهل الدور الذي يؤديه الاستثمار الاجنبي المباشر في دفع عجلة التتمية في الدول

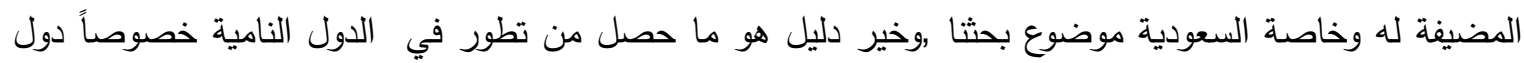
جنوب شرق آسيا ودول جنوب شرق أوروبا ,الاقتصاديات التي تمر بمرحلة انتقالية ورابطة الدول المستقلة, عندما استضافت الشركات المتعددة الجنسيات صاحبة الاستثمار الاجنبي المباشر والتي تحمل في طياتها التكنولوجيا 


\section{ثانيا: تطور الاستثمار الأجنبي المباشر في السعودية}

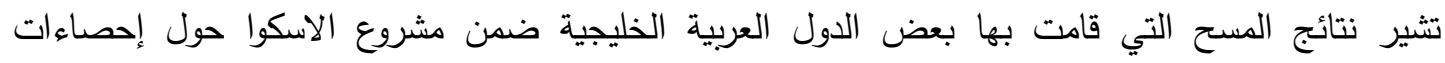

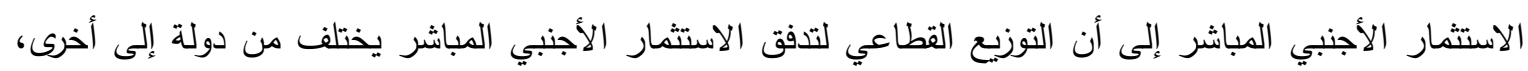

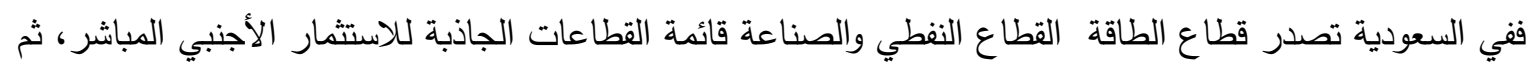
يليه قطاع العقار وأنشطة الأعمال. [7].وتوفر السعودية فرصا استثمارية في قطاعات مختلفة خصوصا قطاعات الطاقة, تكنولوجيا المعلومات, والاتصالات, النقل, الخدمات للوجستية, الصحة, علوم الحياة ,التعليم بتكاليف استثمارية تقديرية ضخمة تقدر ب 200 مليار دولار موزعة على المدن الرئيسية والمدن الاقتصادية روهي مدينة الملك عبد الله

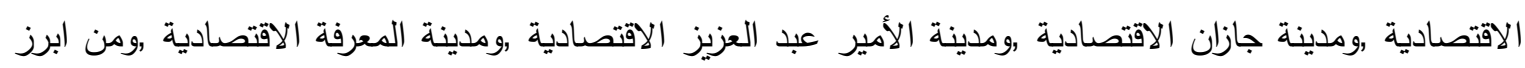
تلك الفرص انتعاش قطاع الإنشاءات في السعودية اكثر من غيرها من دول مجلس التعاون الخليجي رمن خلال تتفيذ التئ

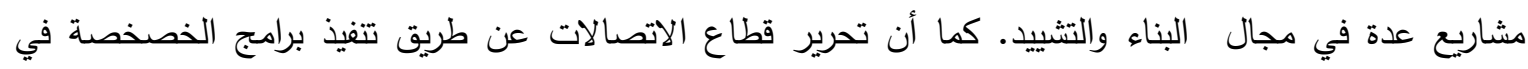

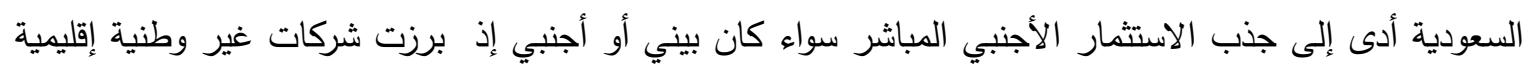
قامت بتتفيذ استثمارات ضخمة في مجال الاتصالات ,فضلا عن بناء ثلاث محطات للطاقة الكهربائية بتكلفة 143 مليار دولار في مدينة الملك عبد الله الاقتصادية ومشروعات قطاع النقل والخدمات اللوجستية بتكلفة ملياري دولار ,ومشروع لصهر الالمنيوم بتكلفة 5-10 مليار دولار [43] دابنه وبالرغم من ذللك إلا إن تدفق الاستثمار الأجنبي المباشر الوارد الى القطاع القاع النفطي الرائد في السعودية يعد منخفضا وكما موضح في جدول 1وكالاتي:- 
Journal of University of Babylon, Pure and Applied Sciences, Vol. (27), No. (1): 2019

جدول1 الناتج المحلي الإجمالي السعودي ومعدلات نموه ونسبة الاستثمار الاجنبي المباشر منه للمدة(1994مليون دولار \% 2017) القيمة: مليون دولار , نسبة التغير ومعدل النمو

\begin{tabular}{|c|c|c|c|c|c|}
\hline معدل النمو السنوي & الاستثمار الاجنبي & معدل النمو & الناتج التغلير في & اجمالي الناتج المحلي & السنة \\
\hline- & 80 & - & - & 123450 & 1994 \\
\hline $1.25-$ & 79 & 15.39 & 190.08 & 142458 & 1995 \\
\hline 5.063 & 83 & 0.139 & 1.99 & 142657 & 1996 \\
\hline 4.819 & 87 & $0.374-$ & -5.34 & 142123 & 1997 \\
\hline 8.045 & 94 & 6.471 & 91.98 & 151321 & 1998 \\
\hline 30.85 & 123 & 12.04 & 182.22 & 169543 & 1999 \\
\hline 48.78 & 183 & 11.77 & 199.72 & 189515 & 2000 \\
\hline 175.4 & 504 & $3.431-$ & -65.03 & 183012 & 2001 \\
\hline $10.11-$ & 453 & 3.026 & 55.39 & 188551 & 2002 \\
\hline 71.74 & 778 & 13.80 & 260.22 & 214573 & 2003 \\
\hline $75.06^{-}$ & 194 & 16.66 & 357.66 & 250339 & 2004 \\
\hline 523.1 & 1209 & 31.10 & 778.67 & 328206 & 2005 \\
\hline 51.28 & 1829 & 8.515 & 279.49 & 356155 & 2006 \\
\hline 32.91 & 2431 & 8.010 & 285.31 & 384686 & 2007 \\
\hline 57.21 & 3822 & 35.12 & 1351.11 & 519797 & 2008 \\
\hline 8.110 & 4132 & $17.44-$ & -906.99 & 429098 & 2009 \\
\hline 12.97 & 4668 & 22.77 & 977.14 & 526812 & 2010 \\
\hline 1.713 & 4748 & 27.08 & 1426.95 & 669507 & 2011 \\
\hline 14.49 & 5436 & 9.626 & 644.49 & 733956 & 2012 \\
\hline 4.341 & 5672 & 1.414 & 103.8 & 744336 & 2013 \\
\hline 18.81 & 6739 & 1.091 & 81.24 & 752460 & 2014 \\
\hline $12.13-$ & 5921 & $14.14-$ & -1064.58 & 646002 & 2015 \\
\hline $18.57-$ & 4821 & $3.490^{-}$ & -225.51 & 623451 & 2016 \\
\hline 17.23 & 5652 & 8.337 & 519.81 & 675432 & 2017 \\
\hline
\end{tabular}

المصدر : تقرير مناخ الاستثمار في الدول العربية للأعوام

المتاح http://www.iaigc.org 2017,2016,2014,2012,2010,2007,2005,2000,1998,1995,1993

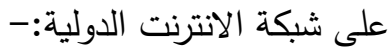

يتضح من خلال بيانات جدول1 بان الاستثمار الأجنبي المباشر الوارد إلى السعودية ومعدلات نموه متذبذبة

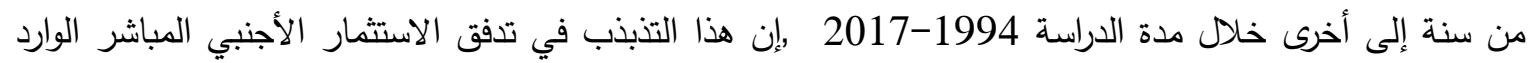

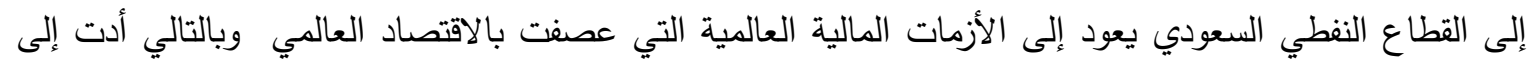

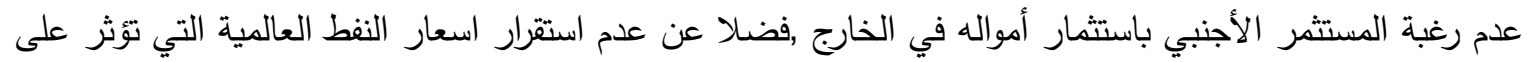

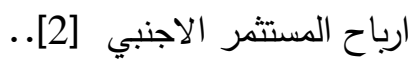


وتبين من الجدول ايضاان نسب التغير في الناتج المحلي الاجمالي في اعوام 1990-2000 كانت متصاعدة الا في بعض السنوات بسبب ازمة الخليج الاولى وحرمان العراق من المورد النفطي وزيادة انتاج السعودية لتعويض النقص الحاصل في السوق النفطية وهكذا كانت الزيادة بعد حرب الخليج الثانية في عام 2003 اذ ازداد نسب التئير التير زيادة متواترة بسبب النقص الحاصل بعد ان كانت الامم المتحدة تصدر النفط العراقي في اتفاقية النفط مقابل الغذاء اضافة

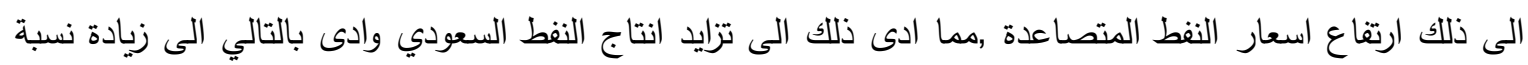
التغير الحاصل في الناتج المحلي الاجمالي , اذ تدل النتائج على الانخفاض الكمي والنوعي للاستثمار الأجنبي المباشر رفي ظل افتقار قانون الاستثمار فيها لكثير من النواقص، ولوجود الكثير من المعوقات القانونية والإدارية.

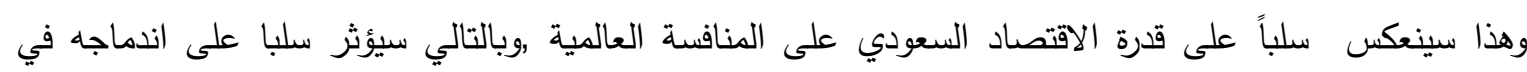
الاقتصاد العالمي في الوقت الذي تتنافس فيه الدول لتحقيق هذا الاندماج والاستفادة منه قدر المستطاع.

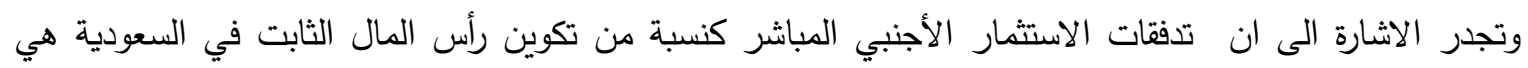

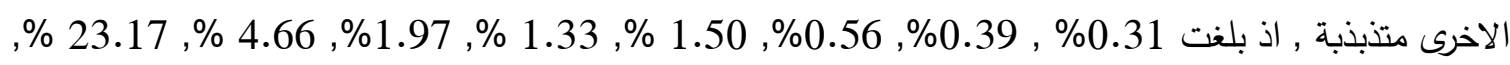

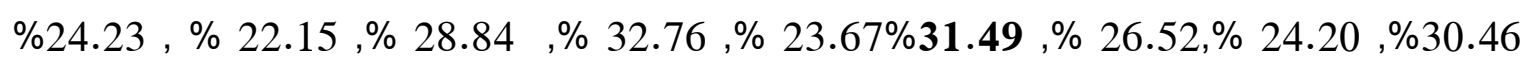

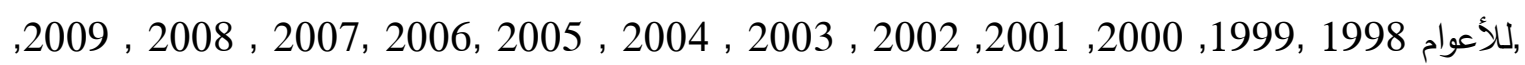
2010, 2014, 2015, 2016, 2017 [11: 2016 اذ إن هذه النسب تدل على أنه من الناحية المالية استطاع الاستثار الأجنبي المباشر أن يساهم مساهمة كبيرة في

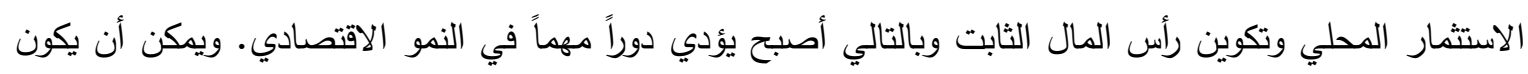
للاستثمار الأجنبي المباشر تأثيراً ايجابياً على الجانب المالي الاستثماري وهو أحد الأهداف التي ترمي إليها السعودية من جذب هذا الاستثمار الأجنبي

\section{المبحث الرابع: التحليل والمناقشة}

\section{اولا:- توصيف النموذج القياسي}

المتغير التابع: يمثل المتغير التابع الاستثمار الاجنبي المباشر ورمزنا له بالرمز FDI مقدرا بملايين الدولارات الامريكية.

المتغيرات المستقلة/ يمثل المتغيرات المستقلة متغيرات متباطئة زمنيا وهو نسبة التغير الحاصلة في الناتج

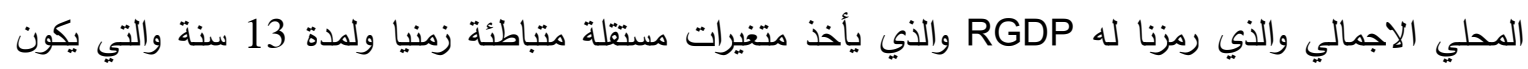
رمزها RGDPt-s والرمز S يمثل سنوات التخلف. ثانيا":- الصيغة الرياضية للنموذج ان الصيغة الخطية هي الصيغة الانسب والافضل لنموذج التباطئات الزمنية وتكون الصيغة كما يأتي:$\mathrm{FDI}=\beta_{0}+\beta_{1} \mathrm{RGDP}_{\mathrm{t}}+\beta_{2} \mathrm{RGDP}_{\mathrm{t}-1}+\beta_{3} \mathrm{RGDP}_{\mathrm{t}-2}+\cdots \ldots \ldots .+\beta_{\mathrm{n}} \mathrm{RGDP}_{\mathrm{t}-\mathrm{s}}+\mathrm{U}_{\mathrm{t}}$ 
ان من نماذج التباطئات الزمنية للمتغيرات المستقلة نموذجين مشهورين ويعدان من افضل النماذج التي تقدر العلاقة ما بين المتغيرات المستقلة والتابع وهما:

Adhcock's Model نموذج ادهوك -A يقدر ادهوك العلاقة المتباطئة زمنيا بشكل مراحل اذ يدخل في كل مرحلة متغيرا متباطئا زمنيا واحدة في حالة كون النتائج المتحصل عليها في المرحلة السابقة جيدة وهكذا يستمر الى نهاية المدة المتباطئة زمنيا والمحدد كما اشرنا اليها سلفا.

Delwees Model نموذج ديليو - B نموذج ديليو يعتمد على تخفيض القيم المتباطئة زمنيا باستخدام طرق تسمى بطرق الاوزان الاعتباطية حتى دئى

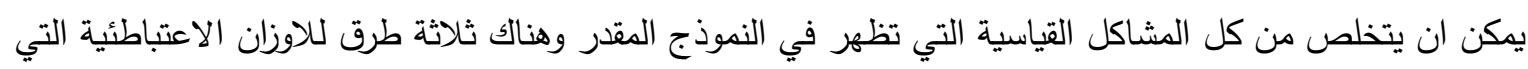
استخدمها ديليو وهي كما ياتي: 1- طريقة المنحنى التنازلي : تكمن هذه الطريقة بضرب المتغيرات المستقل المتباطئة زمنيا بوزن على متوالية

$$
\begin{aligned}
& \text { هندسية من القيم الصغير وكما في النموذج الاتي : } \\
& F D I=\beta_{0}+\beta_{1}\left(R G D P_{t}+\frac{1}{2} R G D P_{t-1}+\frac{1}{4} R G D P_{t-2}+\frac{1}{6} R G D P_{t-3}+\frac{1}{8} R G D P_{t-4}\right.
\end{aligned}
$$$$
\left.+\frac{1}{10} R G D P_{t-5}+\cdots \ldots+\frac{1}{26} R G D P_{t-13}\right)+U_{t}
$$

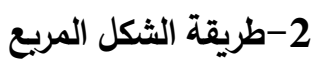

وفي هذه الطريقة تضرب المتغيرات المستقلة المتباطئة زمنيا بوزن ثابت وكما في الصيغة الرياضية للطريقة :

$$
\begin{gathered}
F D I=\beta_{0}+\beta_{1}\left(\left(R G D P_{t}+\frac{1}{3} R G D P_{t-1}+\frac{1}{3} R G D P_{t-2}+\frac{1}{3} R G D P_{t-3}+\frac{1}{3} R G D P_{t-4}\right.\right. \\
\left.+\frac{1}{3} R G D P_{t-5}+\cdots \ldots+\frac{1}{3} R G D P_{t-13}\right)+U_{t}
\end{gathered}
$$

V

تقوم هذه الطريقة بضرب المتغيرات المستقلة المتباطئة زمنيا بوزن يتصاعد تدريجيا ثم يثبت ومن ثم ينخفض

$$
\text { تدريجيا وكما ياتي: }
$$

$$
\begin{aligned}
& F D I=\beta_{0}+\beta_{1}\left(\left(R G D P_{t}+\frac{1}{14} R G D P_{t-1}+\frac{1}{12} R G D P_{t-2}+\frac{1}{10} R G D P_{t-3}+\frac{1}{8} R G D P_{t-4}\right.\right. \\
& +\frac{1}{6} R G D P_{t-5}+\frac{1}{4} R G D P_{t-6}+\frac{1}{2} R G D P_{t-7}+\frac{1}{4} R G D P_{t-8}+\frac{1}{6} R G D P_{t-9} \\
& \left.+\frac{1}{8} R G D P_{t-10}+\frac{1}{10} R G D P_{t-11}+\frac{1}{12} R G D P_{t-12}+\frac{1}{14} R G D P_{t-13}\right)+U_{t} \\
& \text { وعندما قدر ديليو دواله للاستثمار الثلاثة وجد ان افضل تقدير هو دالة الاستثمار بطريقة مقلوب } \\
& \text { رابعا":- تقدير نموذج ادهوك دئو دوله }
\end{aligned}
$$

سيقتصر التحليل على تقدير نموذج ادهوك وقبل ان يتم التقدير يجب علينا ان نأخذ التباطئات الزمنية لنسبة التغير

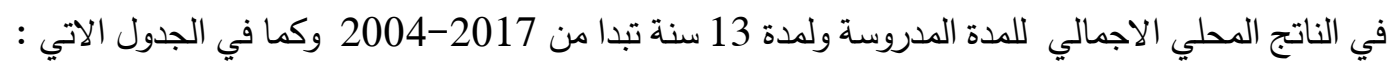


جدول 2 قيم المتغيرات المستقلة المتباطئة زمنيا لنسبة التغير في الناتج المحلي الاجمالي ولمدة 13 سنة للمدة 2017-1994

\begin{tabular}{|c|c|c|c|c|c|c|c|c|c|c|c|c|c|}
\hline $\operatorname{RGDP}_{t}$ & $R G D P_{t-}$ & $R G D P_{t}$ & $R G D P_{t}$ & $R G D P_{t-}$ & $R_{G D P_{t-}}$ & $R G D P_{t-}$ & $R G D P_{t-}$ & $R G D P_{t-}$ & $R G D P_{t-}$ & $\operatorname{RGDP}_{t-1}$ & $R_{G D P} P_{t-1}$ & $R_{G D P_{t-1}}$ & $R G D P_{t-1}$ \\
\hline$*$ & & & & & & & & & & & & & \\
\hline $\begin{array}{r}190.0 \\
8\end{array}$ & $*$ & & & & & & & & & & & & \\
\hline 1.99 & $\begin{array}{r}190.0 \\
8\end{array}$ & $*$ & & & & & & & & & & & \\
\hline-5.34 & 1.99 & $\begin{array}{r}190.0 \\
8\end{array}$ & * & & & & & & & & & & \\
\hline 91.98 & -5.34 & 1.99 & $\begin{array}{r}190.0 \\
8\end{array}$ & * & & & & & & & & & \\
\hline $\begin{array}{r}182.2 \\
2\end{array}$ & 91.98 & -5.34 & 1.99 & $\begin{array}{r}190.0 \\
8\end{array}$ & $*$ & & & & & & & & \\
\hline $\begin{array}{r}199.7 \\
2\end{array}$ & $\begin{array}{r}182.2 \\
2\end{array}$ & 91.98 & -5.34 & 1.99 & $\begin{array}{r}190.0 \\
8\end{array}$ & * & & & & & & & \\
\hline 65.03 & $\begin{array}{r}199.7 \\
2\end{array}$ & $\begin{array}{r}182.2 \\
2\end{array}$ & 91.98 & -5.34 & 1.99 & $\begin{array}{r}190.0 \\
8\end{array}$ & $*$ & & & & & & \\
\hline 55.39 & 65.03 & $\begin{array}{r}199.7 \\
2\end{array}$ & $\begin{array}{r}182.2 \\
2\end{array}$ & 91.98 & -5.34 & 1.99 & $\begin{array}{r}190.0 \\
8\end{array}$ & $*$ & & & & & \\
\hline $\begin{array}{r}260.2 \\
2\end{array}$ & 55.39 & 65.03 & $\begin{array}{r}199.7 \\
2\end{array}$ & $\begin{array}{r}182.2 \\
2\end{array}$ & 91.98 & -5.34 & 1.99 & $\begin{array}{r}190.0 \\
8\end{array}$ & $*$ & & & & \\
\hline $\begin{array}{r}357.6 \\
6\end{array}$ & $\begin{array}{r}260.2 \\
2\end{array}$ & 55.39 & 65.03 & $\begin{array}{r}199.7 \\
2\end{array}$ & $\begin{array}{r}182.2 \\
2\end{array}$ & 91.98 & -5.34 & 1.99 & $\begin{array}{r}190.0 \\
8\end{array}$ & $*$ & & & \\
\hline $\begin{array}{r}778.6 \\
7\end{array}$ & $\begin{array}{r}357.6 \\
6\end{array}$ & $\begin{array}{r}260.2 \\
2\end{array}$ & 55.39 & 65.03 & $\begin{array}{r}199.7 \\
2\end{array}$ & $\begin{array}{r}182.2 \\
2\end{array}$ & 91.98 & -5.34 & 1.99 & 190.08 & $*$ & & \\
\hline $\begin{array}{r}279.4 \\
9\end{array}$ & $\begin{array}{r}778.6 \\
7\end{array}$ & $\begin{array}{r}357.6 \\
6\end{array}$ & $\begin{array}{r}260.2 \\
2\end{array}$ & 55.39 & $\begin{array}{r}- \\
65.03\end{array}$ & $\begin{array}{r}199.7 \\
2\end{array}$ & $\begin{array}{r}182.2 \\
2\end{array}$ & 91.98 & -5.34 & 1.99 & 190.08 & * & \\
\hline $\begin{array}{r}285.3 \\
1 \\
\end{array}$ & $\begin{array}{r}279.4 \\
9 \\
\end{array}$ & $\begin{array}{r}778.6 \\
7 \\
\end{array}$ & $\begin{array}{r}357.6 \\
6 \\
\end{array}$ & $\begin{array}{r}260.2 \\
2 \\
\end{array}$ & 55.39 & $\begin{array}{r}- \\
65.03\end{array}$ & $\begin{array}{r}199.7 \\
2 \\
\end{array}$ & $\begin{array}{r}182.2 \\
2 \\
\end{array}$ & 91.98 & -5.34 & 1.99 & 190.08 & $*$ \\
\hline $\begin{array}{r}1351 . \\
11 \\
\end{array}$ & $\begin{array}{r}285.3 \\
1 \\
\end{array}$ & $\begin{array}{r}279.4 \\
9 \\
\end{array}$ & $\begin{array}{r}778.6 \\
7 \\
\end{array}$ & $\begin{array}{r}357.6 \\
6 \\
\end{array}$ & $\begin{array}{r}260.2 \\
2 \\
\end{array}$ & 55.39 & $\begin{array}{r}-\overline{-} \\
\end{array}$ & $\begin{array}{r}199.7 \\
2 \\
\end{array}$ & $\begin{array}{r}182.2 \\
2 \\
\end{array}$ & 91.98 & -5.34 & 1.99 & 190.08 \\
\hline $\begin{array}{r}- \\
906.9 \\
9\end{array}$ & $\begin{array}{r}1351 . \\
11\end{array}$ & $\begin{array}{r}285.3 \\
1\end{array}$ & $\begin{array}{r}279.4 \\
9\end{array}$ & $\begin{array}{r}778.6 \\
7\end{array}$ & $\begin{array}{r}357.6 \\
6\end{array}$ & $\begin{array}{r}260.2 \\
2\end{array}$ & 55.39 & 65.03 & $\begin{array}{r}199.7 \\
2\end{array}$ & 182.22 & 91.98 & -5.34 & 1.99 \\
\hline $\begin{array}{r}977.1 \\
4\end{array}$ & $\begin{array}{r}906.9 \\
9\end{array}$ & $\begin{array}{r}1351 . \\
11\end{array}$ & $\begin{array}{r}285.3 \\
1\end{array}$ & $\begin{array}{r}279.4 \\
9\end{array}$ & $\begin{array}{r}778.6 \\
7\end{array}$ & $\begin{array}{r}357.6 \\
6\end{array}$ & $\begin{array}{r}260.2 \\
2\end{array}$ & 55.39 & 65.03 & 199.72 & 182.22 & 91.98 & -5.34 \\
\hline $\begin{array}{r}1426 . \\
95\end{array}$ & $\begin{array}{r}977.1 \\
4\end{array}$ & $\begin{array}{r}906.9 \\
9\end{array}$ & $\begin{array}{r}1351 . \\
11\end{array}$ & $\begin{array}{r}285.3 \\
1\end{array}$ & $\begin{array}{r}279.4 \\
9\end{array}$ & $\begin{array}{r}778.6 \\
7\end{array}$ & $\begin{array}{r}357.6 \\
6\end{array}$ & $\begin{array}{r}260.2 \\
2\end{array}$ & 55.39 & -65.03 & 199.72 & 182.22 & 91.98 \\
\hline $\begin{array}{r}644.4 \\
9\end{array}$ & $\begin{array}{r}1426 . \\
95\end{array}$ & $\begin{array}{r}977.1 \\
4\end{array}$ & $\begin{array}{r}906.9 \\
9\end{array}$ & $\begin{array}{r}1351 . \\
11\end{array}$ & $\begin{array}{r}285.3 \\
1\end{array}$ & $\begin{array}{r}279.4 \\
9\end{array}$ & $\begin{array}{r}778.6 \\
7\end{array}$ & $\begin{array}{r}357.6 \\
6\end{array}$ & $\begin{array}{r}260.2 \\
2\end{array}$ & 55.39 & -65.03 & 199.72 & 182.22 \\
\hline 103.8 & $\begin{array}{r}644.4 \\
9\end{array}$ & $\begin{array}{r}1426 . \\
95\end{array}$ & $\begin{array}{r}977.1 \\
4\end{array}$ & $\begin{array}{r}-\overline{-} \\
906.9\end{array}$ & $\begin{array}{r}1351 . \\
11\end{array}$ & $\begin{array}{r}285.3 \\
1\end{array}$ & $\begin{array}{r}279.4 \\
9\end{array}$ & $\begin{array}{r}778.6 \\
7\end{array}$ & $\begin{array}{r}357.6 \\
6\end{array}$ & 260.22 & 55.39 & -65.03 & 199.72 \\
\hline 81.24 & 103.8 & $\begin{array}{r}644.4 \\
9\end{array}$ & $\begin{array}{r}1426 . \\
95\end{array}$ & $\begin{array}{r}977.1 \\
4\end{array}$ & $\begin{array}{r}906.9 \\
9\end{array}$ & $\begin{array}{r}1351 . \\
11\end{array}$ & $\begin{array}{r}285.3 \\
1\end{array}$ & $\begin{array}{r}279.4 \\
9\end{array}$ & $\begin{array}{r}778.6 \\
7\end{array}$ & 357.66 & 260.22 & 55.39 & -65.03 \\
\hline $\begin{array}{r}- \\
1064 . \\
58\end{array}$ & 81.24 & 103.8 & $\begin{array}{r}644.4 \\
9\end{array}$ & $\begin{array}{r}1426 . \\
95\end{array}$ & $\begin{array}{r}977.1 \\
4\end{array}$ & $\begin{array}{r}906.9 \\
9\end{array}$ & $\begin{array}{r}1351 . \\
11\end{array}$ & $\begin{array}{r}285.3 \\
1\end{array}$ & $\begin{array}{r}279.4 \\
9\end{array}$ & 778.67 & 357.66 & 260.22 & 55.39 \\
\hline $\begin{array}{r}- \\
225 . \overline{5} \\
1\end{array}$ & $\begin{array}{r}- \\
1064 . \\
58\end{array}$ & 81.24 & 103.8 & $\begin{array}{r}644.4 \\
9\end{array}$ & $\begin{array}{r}1426 . \\
95\end{array}$ & $\begin{array}{r}977.1 \\
4\end{array}$ & $\begin{array}{r}- \\
906.9 \\
9\end{array}$ & $\begin{array}{r}1351 . \\
11\end{array}$ & $\begin{array}{r}285.3 \\
1\end{array}$ & 279.49 & 778.67 & 357.66 & 260.22 \\
\hline $\begin{array}{r}519.8 \\
1\end{array}$ & $\begin{array}{r}- \\
225.5 \\
1\end{array}$ & $\begin{array}{r}- \\
1064 . \\
58\end{array}$ & 81.24 & 103.8 & $\begin{array}{r}644.4 \\
9\end{array}$ & $\begin{array}{r}1426 . \\
95\end{array}$ & $\begin{array}{r}977.1 \\
4\end{array}$ & $\begin{array}{r}- \\
906.9 \\
9\end{array}$ & $\begin{array}{r}1351 . \\
11\end{array}$ & 285.31 & 279.49 & 778.67 & 357.66 \\
\hline
\end{tabular}




$$
\text { قدر نموذج ادهوك وحسب المراحل ,ونظمت النتائج في الجدول الاتي }
$$

جدول 3 تقدير نموذج ادهوك لأثر نسبة التغير في الناتج المحلي الاجمالي على الاستثمار الاجنبي المباشر للمدة

\section{7-1994}

\begin{tabular}{|c|c|c|c|c|c|c|c|c|c|}
\hline \multicolumn{10}{|c|}{$\begin{array}{l}\text { NUMBER OF SAMPLE SIZE:24 } \\
\text { THE EQUATION TYPE: LAGGED LINEAR } \\
\text { ESTIMATION METHOD: OLS } \\
\text { NUMBER OF STAGS:9 }\end{array}$} \\
\hline $\begin{array}{l}\text { THE STAGS } \\
\text { VARMABLES } \\
\text { AND }\end{array}$ & Stage 1 & Stage 2 & Stage 3 & Stage 4 & Stage 5 & Stage 6 & Stage 7 & Stage 8 & Stage 9 \\
\hline $\begin{array}{c}\text { CONSTANT } \\
\mathrm{T} \\
\end{array}$ & $\begin{array}{c}2557.1 \\
(4.53)^{1 \%}\end{array}$ & $\begin{array}{c}2600.2 \\
(4.16)^{1 \%}\end{array}$ & $\begin{array}{c}2560.2 \\
(3.70)^{1 \%}\end{array}$ & $\begin{array}{c}2137.2 \\
(2.90)^{1 \%}\end{array}$ & $\begin{array}{c}1375.9 \\
(1.79)^{5 \%}\end{array}$ & $\begin{array}{c}392.9 \\
(0.51)^{\text {non }}\end{array}$ & $\begin{array}{c}-205.4 \\
(-0.37)^{\text {non }}\end{array}$ & $\begin{array}{c}-343.7 \\
(-1.11)^{25 \%}\end{array}$ & $\begin{array}{c}-273.9 \\
(-.69)^{25 \%}\end{array}$ \\
\hline $\begin{array}{c}R_{\text {RDP }} \\
\text { T } \\
\text { VIF } \\
\text { TOL }\end{array}$ & $\begin{array}{c}0.1530 \\
(0.17)^{\text {non }}\end{array}$ & $\begin{array}{l}0.1253 \\
(0.13)^{n o n} \\
1.0 \\
1.0\end{array}$ & $\begin{array}{c}0.0866 \\
(0.09)^{n o n} \\
1.0 \\
1.0\end{array}$ & $\begin{array}{c}-0.1639 \\
(-0.18)^{\text {non }} \\
1.0 \\
1.0\end{array}$ & $\begin{array}{l}0.3593 \\
(0.44)^{\text {non }} \\
1.1 \\
0.9\end{array}$ & $\begin{array}{c}0.707 \\
(1.07)^{25 \%} \\
4.2 \\
0.24 \\
\end{array}$ & $\begin{array}{c}0.2144 \\
(0.49)^{\text {non }} \\
3.2 \\
0.31\end{array}$ & $\begin{array}{c}0.1449 \\
(0.69)^{25 \%} \\
6.2 \\
0.16\end{array}$ & $\begin{array}{c}0.1236 \\
(0.47)^{\text {non }} \\
5.1 \\
0.20 \\
\end{array}$ \\
\hline $\begin{array}{c}R G D P_{t-1} \\
\text { T } \\
\text { VIF } \\
\text { TOL }\end{array}$ & & $\begin{array}{l}0.3412 \\
(0.36)^{n o n} \\
1.0 \\
1.0\end{array}$ & $\begin{array}{c}0.2936 \\
(0.31)^{n o n} \\
1.0 \\
1.0\end{array}$ & $\begin{array}{l}0.2431 \\
(0.27)^{n o n} \\
1.0 \\
1.0\end{array}$ & $\begin{array}{c}-0.0535 \\
(-0.07)^{\text {non }} \\
1.0 \\
1.0\end{array}$ & $\begin{array}{c}0.4399 \\
(0.68)^{25 \%} \\
5.7 \\
0.18\end{array}$ & $\begin{array}{c}0.797 \\
(1.87)^{5 \%} \\
6.2 \\
0.16\end{array}$ & $\begin{array}{c}0.4729 \\
(2.18)^{5 \%} \\
9.3 \\
0.11\end{array}$ & $\begin{array}{c}0.4576 \\
(1.69)^{10} \% \\
7.7 \\
0.13\end{array}$ \\
\hline $\begin{array}{c}R G D P_{t-2} \\
\text { T } \\
\text { VIF } \\
\text { TOL }\end{array}$ & & & $\begin{array}{c}0.7382 \\
(0.76)^{25} \% \\
1.0 \\
1.0\end{array}$ & $\begin{array}{c}0.7806 \\
(0.86)^{25 \%} \\
1.0 \\
1.0\end{array}$ & $\begin{array}{c}0.8285 \\
(1.06)^{25 \%} \\
1.0 \\
1.0\end{array}$ & $\begin{array}{c}0.6233 \\
(0.98)^{25 \%} \\
5.8 \\
0.17\end{array}$ & $\begin{array}{c}1.0115 \\
(2.41)^{5 \%} \\
10.6 \\
0.09\end{array}$ & $\begin{array}{c}1.1773 \\
(5.64)^{1 \%} \\
22.5 \\
0.04\end{array}$ & $\begin{array}{c}1.1985 \\
(4.15)^{1 \%} \\
20.1 \\
0.05\end{array}$ \\
\hline $\begin{array}{c}R_{G D P} P_{t-3} \\
\text { T } \\
\text { VIF } \\
\text { TOL }\end{array}$ & & & & $\begin{array}{c}1.978 \\
(1.88)^{5 \%} \\
1.0 \\
1.0\end{array}$ & $\begin{array}{c}2.1301 \\
(2.35)^{5 \%} \\
1.0 \\
1.0\end{array}$ & $\begin{array}{c}2.2664 \\
(3.05)^{1 \%} \\
9.4 \\
0.11\end{array}$ & $\begin{array}{c}1.889 \\
(3.84)^{1 \%} \\
13.9 \\
0.07\end{array}$ & $\begin{array}{c}1.724 \\
(7.00)^{1 \%} \\
25.6 \\
0.039\end{array}$ & $\begin{array}{c}1.7416 \\
(5.03)^{1 \%} \\
22.9 \\
0.043\end{array}$ \\
\hline $\begin{array}{c}R_{G D P} P_{t-4} \\
\text { T } \\
\text { VIF } \\
\text { TOL }\end{array}$ & & & & & $\begin{array}{c}2.3167 \\
(2.42)^{5} \% \\
1.1 \\
0.9\end{array}$ & $\begin{array}{c}2.6323 \\
(3.36)^{1 \%} \\
12.3 \\
0.08\end{array}$ & $\begin{array}{c}2.538 \\
(4.92)^{1 \%} \\
21.8 \\
0.05\end{array}$ & $\begin{array}{c}2.0756 \\
(7.53)^{1 \%} \\
31.6 \\
0.032\end{array}$ & $\begin{array}{c}2.0838 \\
(5.04)^{1} \% \\
27.1 \\
0.037\end{array}$ \\
\hline $\begin{array}{c}R_{G D P} P_{t-5} \\
\text { T } \\
\text { VIF } \\
\text { TOL }\end{array}$ & & & & & & $\begin{array}{c}2.2377 \\
(2.82)^{1 \%} \\
11.6 \\
0.09\end{array}$ & $\begin{array}{c}2.3928 \\
(4.62)^{1 \%} \\
19.4 \\
0.05\end{array}$ & $\begin{array}{c}2.2193 \\
(8.39)^{1 \%} \\
34.1 \\
0.029\end{array}$ & $\begin{array}{c}2.2273 \\
(5.09)^{1} \% \\
27.2 \\
0.036\end{array}$ \\
\hline $\begin{array}{c}R_{G D P} P_{t-6} \\
\text { T } \\
\text { VIF } \\
\text { TOL }\end{array}$ & & & & & & & $\begin{array}{c}2.1767 \\
(4.11)^{1 \%} \\
18.9 \\
0.05\end{array}$ & $\begin{array}{c}2.4521 \\
(9.28)^{1 \%} \\
36.7 \\
0.027\end{array}$ & $\begin{array}{c}2.4173 \\
(7.73)^{1} \% \\
32.9 \\
0.031\end{array}$ \\
\hline $\begin{array}{c}R G D P_{t-7} \\
\text { T } \\
\text { VIF } \\
\text { TOL }\end{array}$ & & & & & & & & $\begin{array}{c}1.666 \\
(5.52)^{1 \%} \\
24.6 \\
0.041\end{array}$ & $\begin{array}{c}1.5847 \\
(2.99)^{1} \% \\
18.6 \\
0.054\end{array}$ \\
\hline $\begin{array}{c}R G D P_{t-8} \\
\text { T } \\
\text { VIF } \\
\text { TOL }\end{array}$ & & & & & & & & & $\begin{array}{c}-0.1460 \\
(-0.22)^{1 \%} \\
4.3 \\
0.23\end{array}$ \\
\hline$R^{2}$ & $0.1 \%$ & $0.8 \%$ & $3.9 \%$ & $22.1 \%$ & $45.8 \%$ & $68 \%$ & $88 \%$ & $97 \%$ & $97 \%$ \\
\hline $\bar{R}^{2}$ & & & & $1.3 \%$ & $25 \%$ & $49 \%$ & $78 \%$ & $94 \%$ & $92 \%$ \\
\hline $\mathbf{R}$ & & & $20 \%$ & $47 \%$ & $68 \%$ & $82 \%$ & $94 \%$ & $99 \%$ & $99 \%$ \\
\hline$F_{(v, 24)}$ & $\begin{array}{c}F_{(2,24)} \\
(0.03)^{n o n}\end{array}$ & $\begin{array}{c}F_{(3,24)} \\
(0.08)^{n o n}\end{array}$ & $\begin{array}{c}F_{(4,24)} \\
(0.23)^{n o n}\end{array}$ & $\begin{array}{c}F_{(5,24)} \\
(1.06)^{n o n}\end{array}$ & $\begin{array}{c}\boldsymbol{F}_{(6,24)} \\
(2.20)^{n o n}\end{array}$ & $\begin{array}{c}\boldsymbol{F}_{(\mathbf{7}, 24)} \\
(3.81)^{5 \%}\end{array}$ & $\begin{array}{c}\boldsymbol{F}_{(\mathbf{8}, \mathbf{2 4})} \\
(\mathbf{9 . 1 5})^{\mathbf{5} \%}\end{array}$ & $\begin{array}{c}\boldsymbol{F}_{(\mathbf{9}, 24)} \\
(\mathbf{3 2 . 8 9})^{1 \%}\end{array}$ & $\begin{array}{c}F_{(10,24)} \\
(18.51)^{1 \%}\end{array}$ \\
\hline D.W & $(0.0665)^{\text {out }}$ & $(0.0745)^{\text {out }}$ & $(0.113)^{o u t}$ & $(0.401)^{o u t}$ & $(0.599)^{\text {out }}$ & $(1.285)^{5 \%}$ & $(2.479)^{5 \%}$ & $(1.781)^{5 \%}$ & $(1.59)^{5 \%}$ \\
\hline & & $(0.0012)$ & $\begin{array}{r}F_{0.01(d} \\
D V\end{array}$ & $\begin{array}{r}0.05(d f .15 \\
=3.89, l \\
5: d l=0.6\end{array}$ & $\begin{array}{l}d f .14)=2 \\
d u=1 .\end{array}$ & $d f .15)=$ & & COOKS DIST & NCE $:<20 \%$ \\
\hline
\end{tabular}


في عالم اليوم في الكثير من الازمات التي تؤثر على اقتصاديات الدول في العالم فانه يودي بالنتيجة الى التأثير على بياناتها وسلوكها المتوافق او غير المتوافق مع فروض النظرية الاقتصادية مما تسبب مشاكل قياسية عدة عند تقدير نماذجه وبما ان النموذج المقدر هو نموذج تباطئ زمني فحتما تكون بياناته في اغلب الاحوال غير مستقرة الا اذ تعاملنا

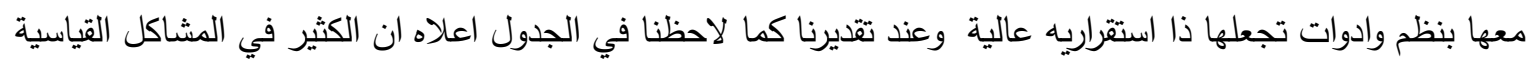
قد لازمت النموذج في مراحل متعددة الا في النموذج المقدر في المرحلة الثامنة اذ تم اختبار بياناته باختبار

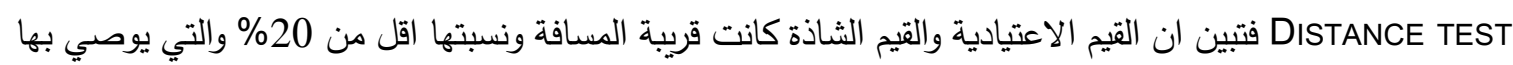
العالم الاحصائي COOKS والتي ظهرت نسبتها التقديرية من النموذج المقدر بحدود 12\% ولذا فان بان بيانات المرحلة

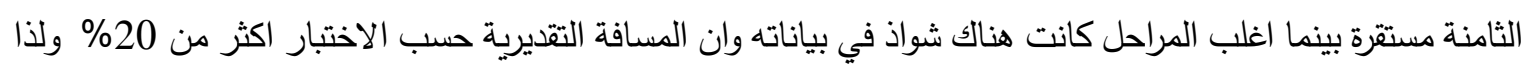
فان هذا النموذج يعتبر الافضل من النماذج وبالتالي سيكون اختياره ليمثل العلاقة ما بين نسبة التغير في الناتج المحلي

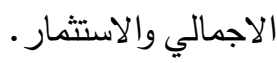

\section{ثبوت المعنوية}

بالاستتاد الى اختبار T تبين ثبوت معنوية معاملات انحدار متغيرات نسبة التغير في الناتج المحلي الاجمالي بالتباطئ الثالث والرابع والخامس والسادس والسابع على مستوى معنوية 1\% بينما ثبتت معنوية معامل انحدار متغير

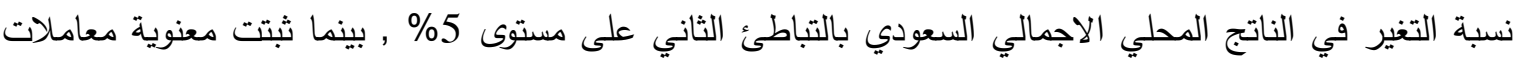

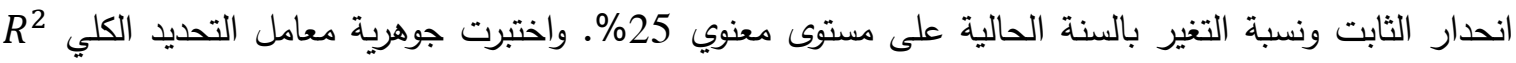

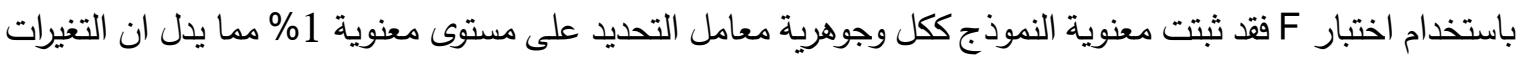
الحاصلة في الاستثمار الاجنبي المباشر في القطاع النفطي سببها نسبة التغير في الناتج المحلي الاجمالي السعودي عبر النبر

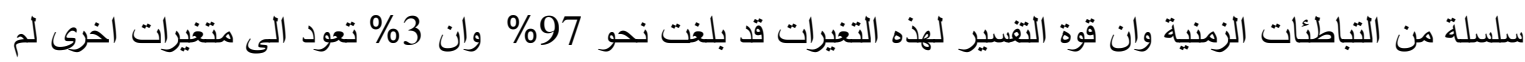

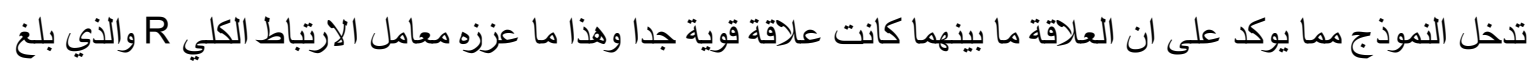

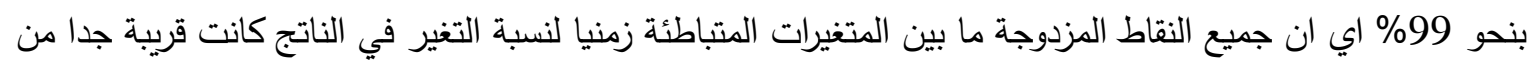
خط الانحدار المقدر والذي يمثل اتجاه النموذج المقدر الخطي.وبالتالي عد م خرق الفرض العشوائي 0 الغئي

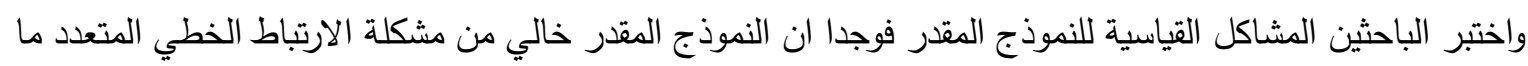

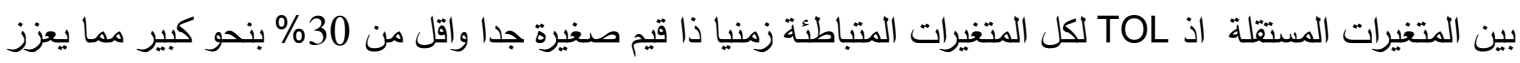
D.W ان النموذج خالي من هذه المشكلة , واختبر كذلك مشكلة الارتباط الذاتي ما بين المتبقيات العشوائية باختبار فكانت القيمة المحتسبة له قد وقعت حسب الهن المخطط الاتي :

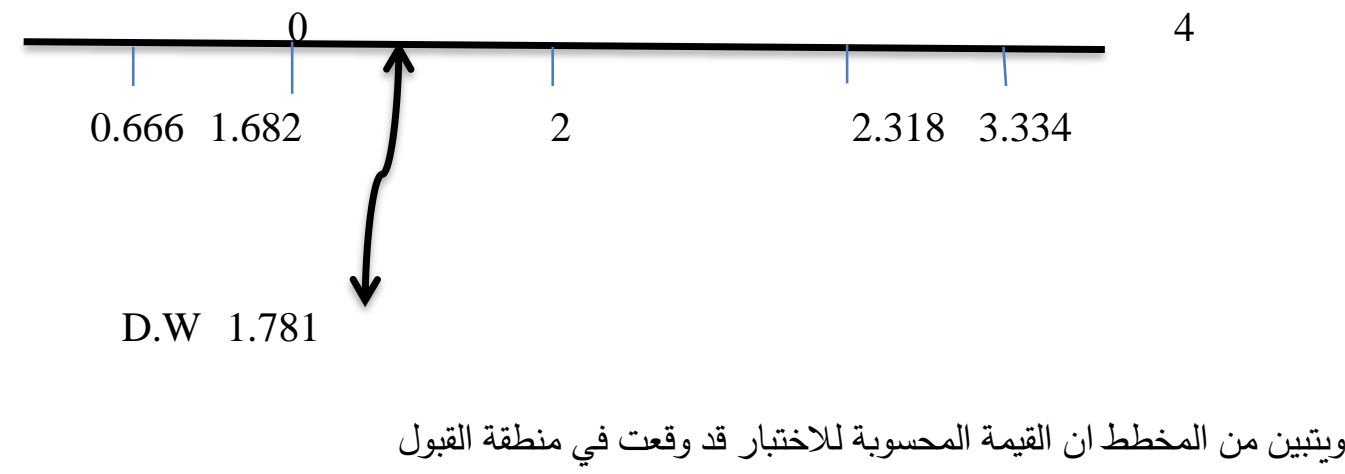


2.318 2.781 > du: 1.682 وبالتالي خلو النموذج المقدر من مشكلة الارتباط الذاتي مابين المتبقيات

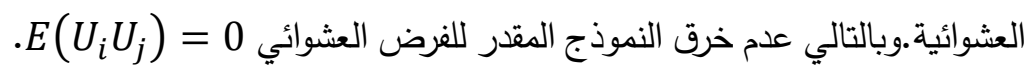

SPEARMAN RANK واختبرت مشكلة عدم ثبات تجانس التباين باختبار معامل ارتباط الرتب لسبيرمان CORRELATION COEFFICIENT

$$
r_{x, u}=1-\frac{\sqrt{6 \sum D_{i}^{2}}}{n\left(n^{2}-1\right)}
$$

والتي بلغت نحو 0.03 مهي قيمة قريبة للصفر جدا مما يعني ان النموذج المقدر لم يخرق الفرض العشوائي $E\left(x_{i} u_{j}\right)=0$ تفسير العلاقات

تبين من التقدير ان جميع المتغيرات ذا اشارة موجبة وعلاقة طردية ما بين نسبة التغيير في الناتج المحلي

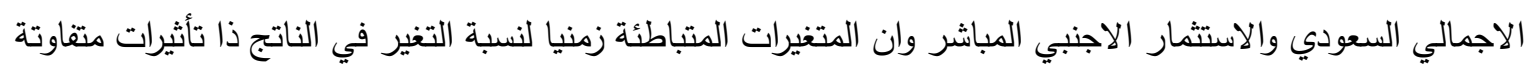

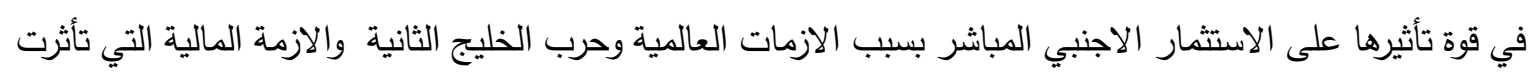

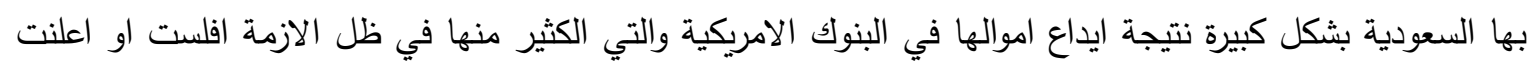

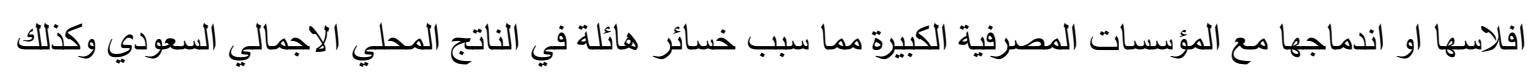

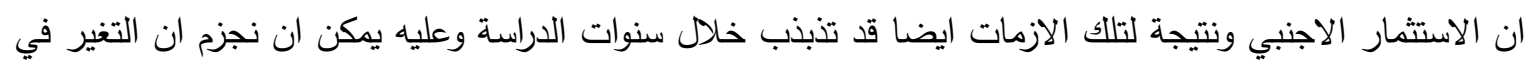

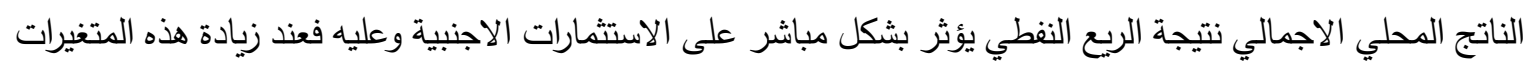

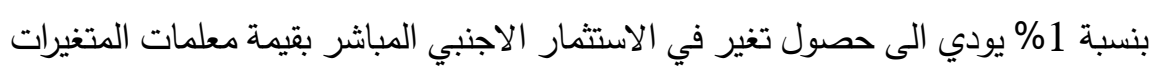
الاستتتاجات والتوصيات أولا: الاستنتاجات: توصل الباحث إلى الاستتتاجات التالية 1- هناك أشكال عدة للاستثمار الأجنبي ,كالاستثمار الأجنبي المباشر وغير المباشر, الاستثمار الباحث عن

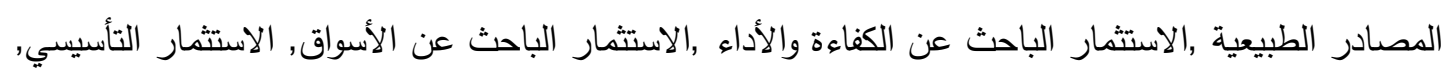

$$
\text { الاستثمار الباحث عن أصول استراتيجية وغيرها. }
$$

2-شهر الاقتصاد السعودي بشكل خاص عدم وضوح الرؤية في بعض السياسات الحكومية, التي تعد من أهم

$$
\text { معوقات توفر المناخ الاستثماري الملائم. }
$$

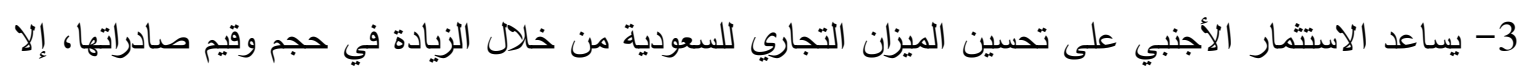

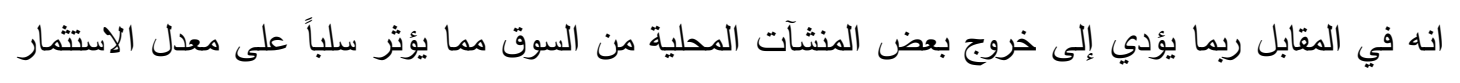

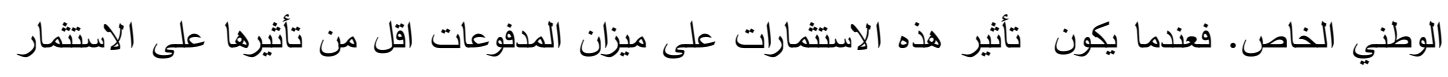

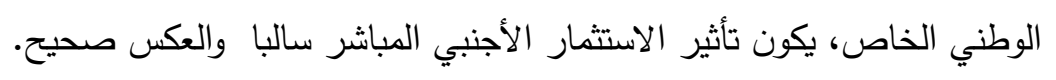

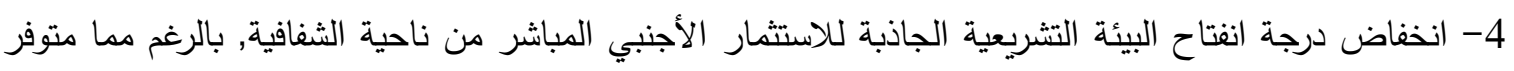

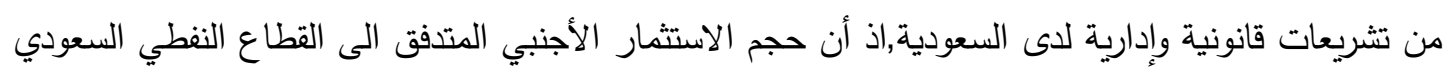
شهد تذبذب وعدم استقرار معدلات نموه السنوي لا سباب عدة.

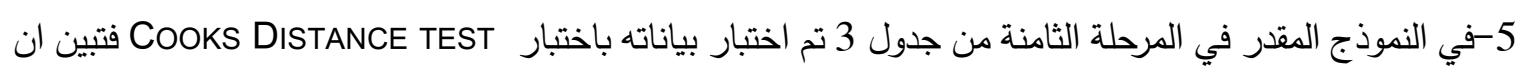

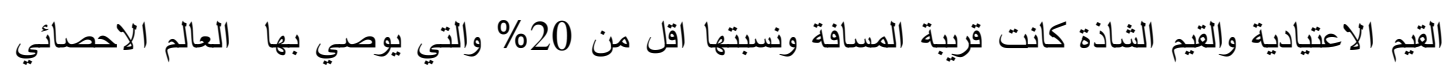


COOKS والتي ظهرت نسبتها التقديرية من النموذج المقدر بحدو 12\% ولذا فان بيانات المرحلة الثامنة مستقرة

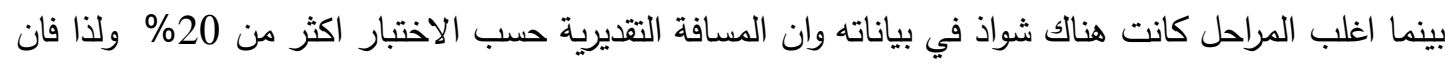
هذا النموذج يعتبر الافضل من النماذج وبالتالي سيكون اختياره ليمثل العلاقة ما بين نسبة التغير في الناتج المحلي

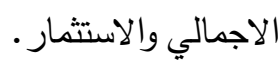
6-بالاستتاد الى اختبار T تبين ثبوت معنوية معاملات انحدار متغيرات نسبة التغير في الناتج المحلي الاجمالي

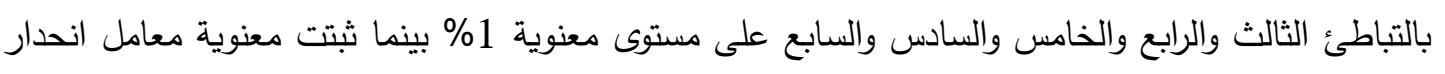

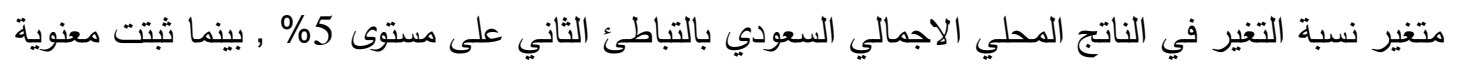

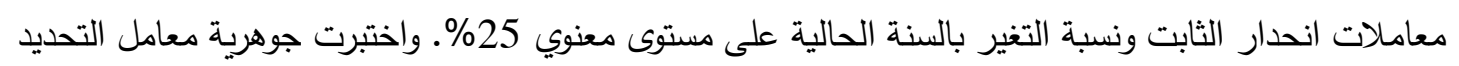

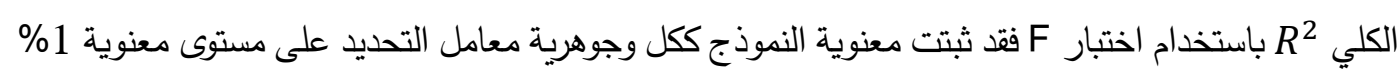
7- ان التغيرات الحاصلة في الاستثمار الاجنبي المباشر في القطاع النفطي سبيها نسبة التغير في الناتج المحلي

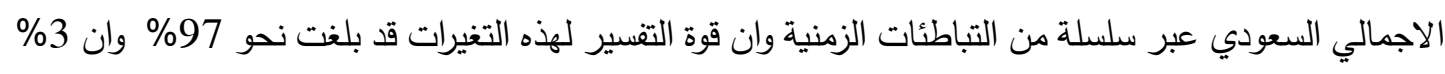

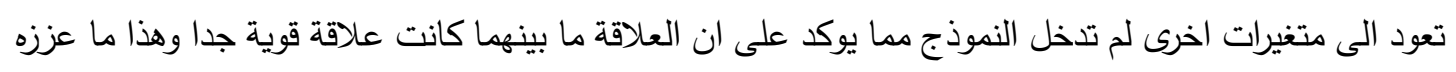

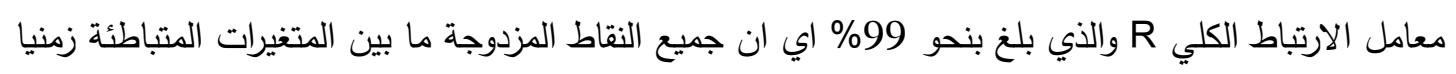

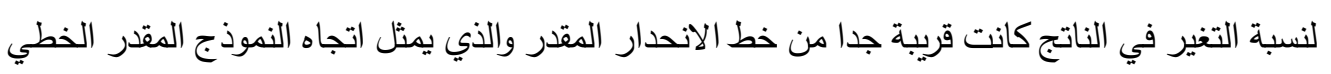
8-ان التغير في الناتج المحلي الاجمالي نتيجة الريع النفطي يؤثر بشكل مباشر على الاستثمارات الاجنبية وعليه فعند زيادة هذه المتغيرات بنسبة 1\% يودي الى حصول تغير في الاستثار الاجنبي المباشر بقيمة معلمات المتغيرات. ثانيا التوصيات:

1-ضرورة وجود سياسة ائتمانية واضحة ومعلنة في السعودية لتفعيل دور المصارف والمؤسسات المالية في توفير التمويل للمشروعات الاستثارية من خلال القروض المتوسطة وطويلة الأجل وكذلك التسهيلات الائتمانية المصرفية لتوفير رأس المال العامل لتلات المشروعات. 2- ضرورة وضع أنظمة معلومات للقطاعات الاقتصادية السعودية كافة, فضلا عن توفير الإحصاءات الدورية

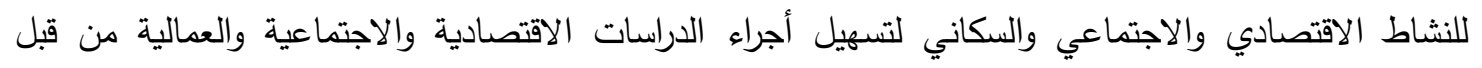
المستثمرين لمعرفة طبيعة السوق وأنماط الاستهلاك وما يتوفر من الموارد الاقتصادية المختلفة القابلة للاستغلال وحجم القوى العاملة وتركيبتها وطبيعتها. 


\section{CONFLICT OF INTERESTS.}

\section{There are non-conflicts of interest .}

\section{ثبت المراجع العربية والاجنبية}

1- أسار فخري عبد اللطيف ,العمل المصرفي والاستثمار من اجل التتمية, مجلة علوم إنسانية ,ألسنه

$$
\text { الثالثة,العدد26, } 2006 \text {,ص27 }
$$

2- الأمانة العامة لجامعة الدول العربية وآخرون,التقرير الاقتصادي العربي الموحد, أبو ظبي ، 2004,ص23

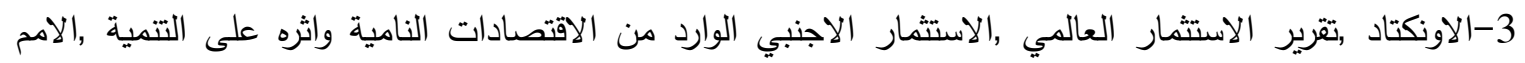

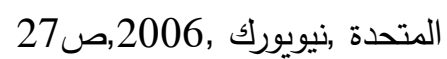

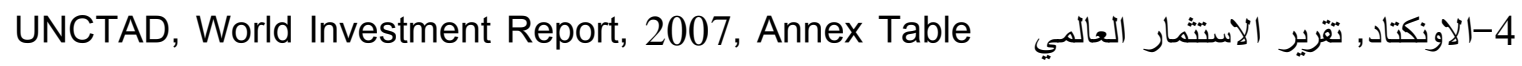

5-اللجنة الاقتصادية والاجتماعية لغربي أسيا (الاسكوا) سياسات الاستثمار الأجنبي المباشر والبيني في منطقة

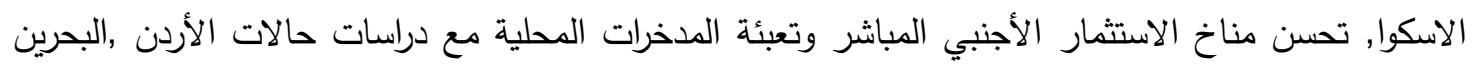

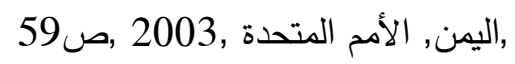

6-اللجنة الاقتصادية والاجتماعية لغربي آسيا (الاسكوا) ,الاستعراض السنوي للتطورات في مجال العولمة والتكامل

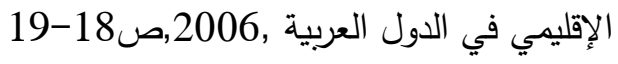

7- الجنة الاقتصادية والاجتماعية لغربي أسيا (الاسكوا) , الاستعراض السنوي للتطورات في مجال العولمة والتكامل

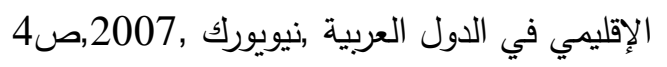

8- المؤسسة العربية لضمان الاستثمار , تقرير مناخ الاستثمار للدول العربية , ,الكويت, 2000 , ص23. صائس

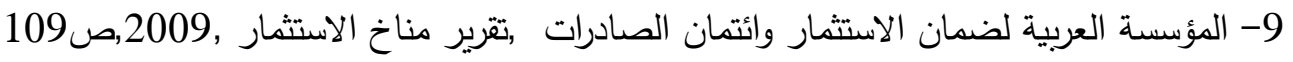
10 - امجد صباح عبد العالي ,أساليب نقل التكنولوجيا إلى دول مجلس التعاون الخليجي ردراسة تقويمية ,مجلة

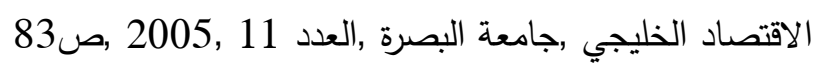

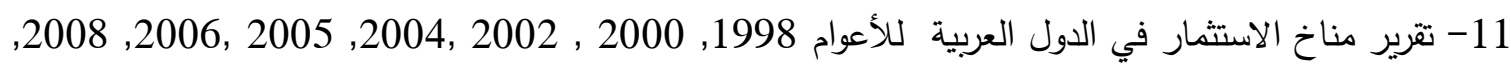

$$
\text { 2010, 2012, 2013, 2014, 2016, } 2017 .
$$

12- حسين عبد المطلب الاسرج , آليات تحفيز الاستثار الأجنبي المباشر إلى الدول العربية,بحث مقدم إلى جامعة الزقازيق ,مصر , ص 22-23 , المتاح على شبكة الانترنت

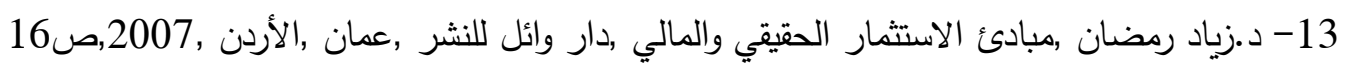

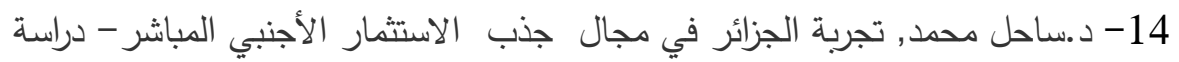

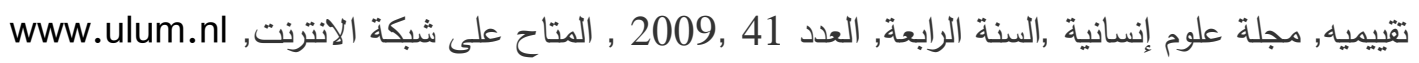

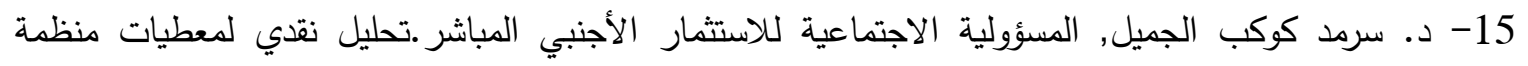

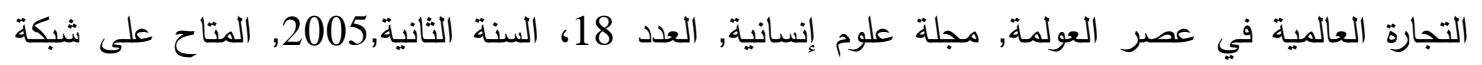
الانترنت, 16- صندوق النقد العربي، مساهمة صندوق النقد العربي في تطوير الأسواق المالية العربية،أبو ظبي،2003، 
17-د. عباس جبار الشرع , دور الاستثمار الأجنبي المباشر في حركة التصنيع العربي , رمجلة علو م اقتصادية

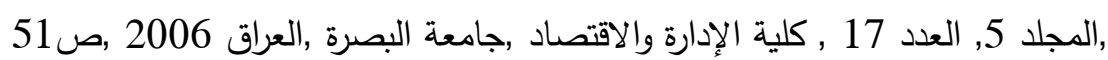
18-عبد السلام احمد ابو قحف ,السياسات والاشكال المختلفة للاستثمارات الاجنبية ,الجزء الرابع, مؤسسة شباب

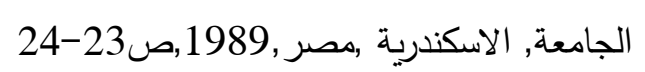

19- عبد السلام احمد ابو قحف، اقتصاديات الأعمال والاستثمار الدولي، دار الجامعة الجديدة، الإسكندرية، مصر ،

$$
\text { 2003, ص } 42
$$

20 ×عرفان تقي الحسن، التمويل الدولي، الطبعة الثانية، عمان, 2002، ص ص 45. 21-عبدوس عبد العزيز , سياسة الانفتاح التجاري بين محاربة الفتر وحماية البيئة , مجلة الباحث , العدد 8,جامعة

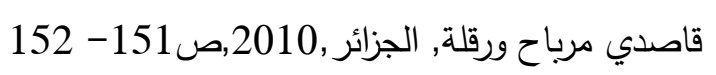

22-عدنان الهندي، تمويل المشاريع باستخدام صيغة رأس المال المبادرة، إصدار اتحاد المصارف العربية، بيروت

$$
32 \text { - 2000، صن } 28
$$

23- د. علي احمد بلبل ومحمد مصطفى عمران ,الاستثمارات الأجنبية المباشرة ,التطور المالي والنمو الاقتصادي

$$
\text { ,شواهد من البلدان العربية , أوراق صندوق النقد العربي ,العدد } 6 .
$$

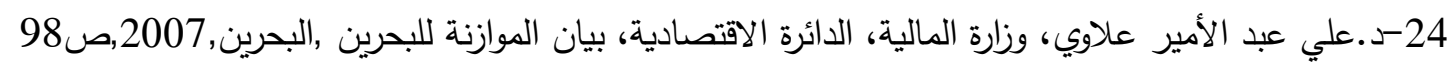

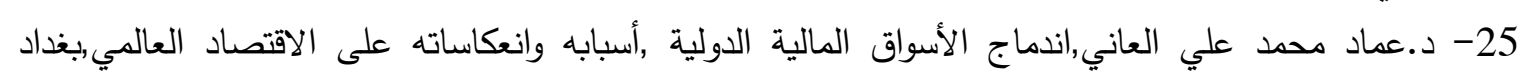

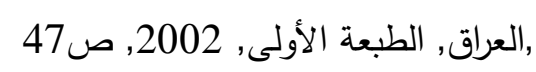

26- د. عماري جمعي, العولمة المالية وآثارها على الدول النامية, مجلة علوم إنسانية, السنة الرابعة ,العدد 33 ,

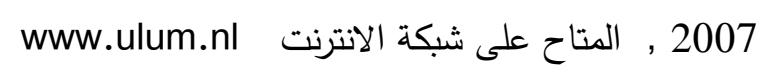

27-عوني محمد الفخري، التتظيم القانوني للشركات متعددة الجنسية والعولمة، إصدارات بيت الحكمة، ط 1، بغداد،

$$
\text { . 2002، ص صن } 13
$$

28-د.فلاح خلف علي الربيعي, أثر السياسات الاقتصادية على مناخ الاستثمار في الدول العربية,مجلة علوم إنسانية

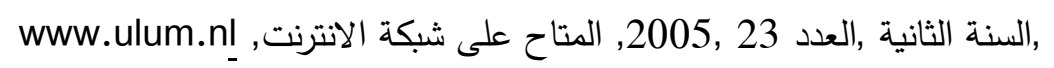

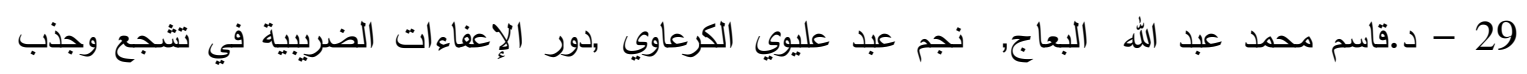

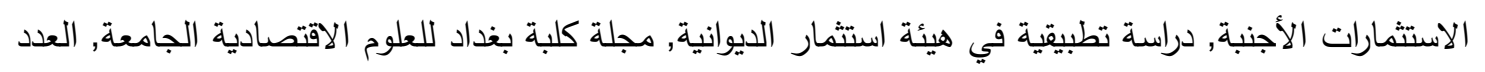

$$
\text { 40 4014, 2014, ص20 315-316 }
$$

30- د. قلش عبد الله, بدائل تمويل المؤسسة في ظل العولمة المالية,مجلة علوم إنسانية ,السنة الرابعة, العدد 32 ,

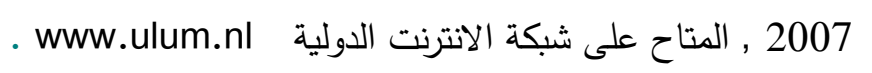

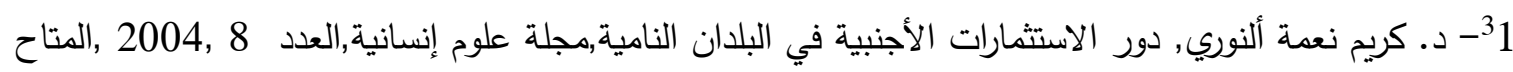

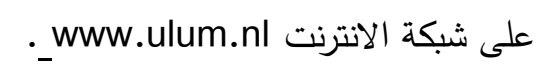

32- كريم نعمة ألنوري ,مكانة البلدان العربية في المؤشرات العالمية ,مجلة علوم إنسانية العدد30, أيلول, 2006,

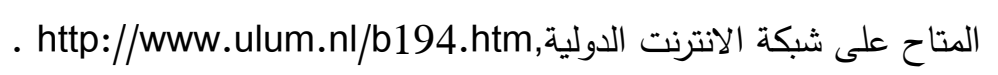

33-محمد العريان ,ومحمد الجمال ,جذب الاستثمار الاجنبي المباشر الى الدول العربية ,ندوة الحوافز الممنوحة

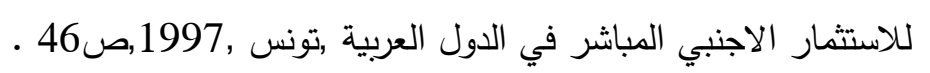

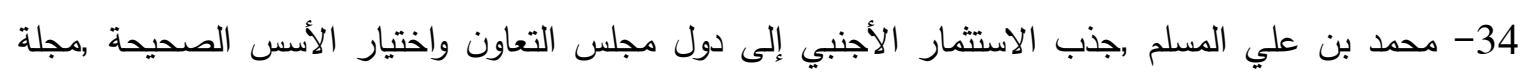

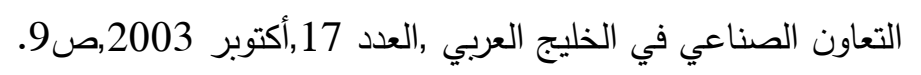




$$
\begin{aligned}
& \text { 35- محمد كمال الحمزاوي, سوق الصرف الأجنبي ,منشاة المصارف,الإسكندرية ,مصر , } 2004 \text { ص21. } \\
& \text { 36- محمد صقر، سمير شرف، الاستثمارات الأجنبية المباشرة ودورها في تتمية الاقتصاديات النامية (FDI)، مجلة } \\
& \text { جامعة تشرين للدراسات والبحوث العلمية، المجلد 28، العدد 3، جامعة تشرين للدراسات والبحوث العلمية, }
\end{aligned}
$$

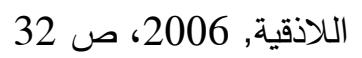

$$
\begin{aligned}
& \text { 37- د. منصوري الزين, دور الاستتمارات العربية البينية في تفعيل التكامل الاقتصادي العربي,مجلة علوم إنسانية }
\end{aligned}
$$

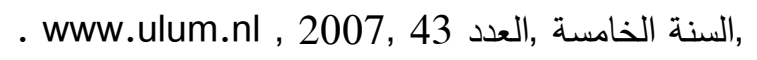

$$
\begin{aligned}
& 38 \text { - ناجي حسين, تقييم مناخ الاستثمار الأجنبي في الجزائر ,.مجلة علوم إنسانية ,السنة الثالثة ,العدد 24, } 2005
\end{aligned}
$$

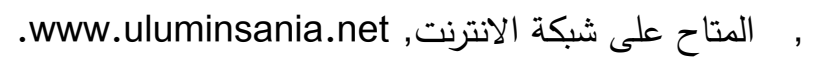

$$
\begin{aligned}
& \text { 39- د. نوزاد عبد الرحمن إلهيتي, الثركات متعددة الجنسية ودورها في الاقتصاد العالمي, مجلة علوم إنسانية ,السنة }
\end{aligned}
$$

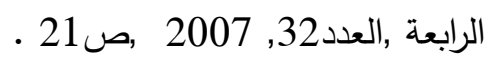

$$
\begin{aligned}
& \text { 40- د. هناء عبد الغفار السامرائي، الاستثمار الأجنبي المباشر والتجارة الدولية الصين أنموذجا، إصدارات بيت }
\end{aligned}
$$

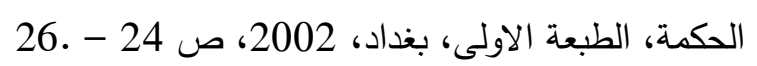

$$
\begin{aligned}
& 41 \text { - هيثم عبد الله سلمان , تقييم الخصخصة في دول مجلس التعاون الخليجي,جامعة البصرة ,كلية الإدارة }
\end{aligned}
$$

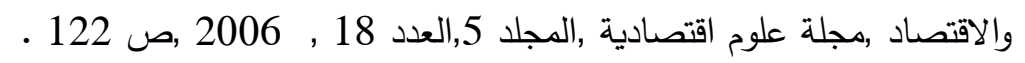

$$
\begin{aligned}
& \text { 42-د.هيل عجمي جميل ,الاستثمار الأجنبي المباشر الخاص في الدول النامية ,الحجم والاتجاه والمستقبل ,مركز }
\end{aligned}
$$

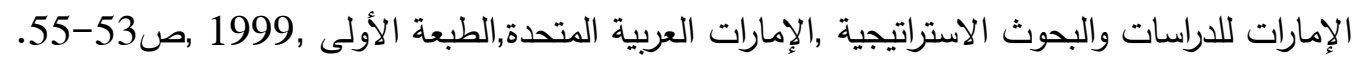

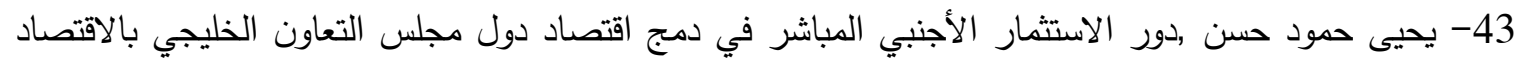

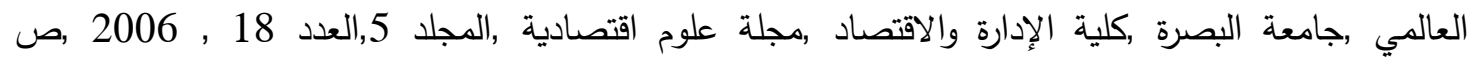

$$
\begin{aligned}
& \text { ص80-81. }
\end{aligned}
$$

44- Babatunde, Shakirat Adepeju, The Impact of Tax Incentives on Foreign Direct Investment in Oil and Gas Sector in Nigeria, University Of Lagos School Of Post Graduate Studies ,IOSR Journal of Business and Management (IOSR-JBM, ISSN: 2278-487X.Volume 6, Issue 1 (Nov. - Dec. 2012), , from the website:www.iosrjournals.org/...6-issue1/A0610115.pdf?id=5352.

45-Ekperiware C. Moses m, Oil and Nonoil FDI and Economic Growth in Nigeriam, Journal of Emerging Trends in Economics and Management Sciences (JETEMS) 2(4):333-343 (ISSN:2141-7024), Technology Innovation and Enterprise Studies (TIES) Department National Centre for Technology Management (NACETEM), Obafemi Awolowo University (OAU), Ile-Ife Nigeria,2012,pp34 .

46-.Gaber Mohamed Abdel Gawad, Foreign Direct Investment (FDI) and Its Effects On Oil, G as And Refinery Production and Their Exports: An Applied Study, Journal of Economics and Sustainable Development, ISSN 2222-1700 (Paper) ISSN 22222855, Vol.4, No.1, 2013. from the website:www.iiste.org/.../index.php/JEDS/article/viewFileForeign Direct Investment (FDI) and Its Effects On Oil, Gas And Refinery Production and Their Exports: An Applied Study.... Foreign Direct Investment, Oil and Gas Production and Refinery.

47-Laura Alfaro, Foreign Direct Investment and Growth: Does the Sector Matter, April 2003, from the website:www.grips.ac.jp/teacher/oono/hp/docu01/paper14.pdf 
48- Kolawole Olayiwola, FOREIGN DIRECT INVESTMENT, NON-OIL EXPORTS, AND ECONOMIC GROWTH IN NIGERIA: A CAUSALITY ANALYSIS1, Department of Economics and Development Studies Covenant University, Ota, Ogun State, Nigeria, Asian Economic and Financial Review, 2013, from the website:www.researchgate.net/...n/229050643_Foreign_direct

Email: irjmss@gmail.com Barua (2013) and in Nigeria by Enimola (2011), and Olayiwola and Okodua (2013) and in Ghana by Abor et al (2008) who found positive effect of FDI on exports of those

49-Mark J. Kaiser Allan G. Pulsipher, A review of the oil and gas sector in Kazakhstan ,2006 , from the website:https://www.sciencedirect.com/science/article/pii/S0301421506001443

50- Mustapha Hussain I, Abdullahi Ahmed Mohammed, Oil and Non-Oil Foreign Direct Investment and Economic Growth in Nigeria: An Empirical Evidence from Autoregressive Distributed Lag Model ,2011, from the website:www.sapub.org/...rpdf.aspx?doi=10.5923/j.economics...

Abstract The paper examines the impact of both oil and non-oil foreign direct investment (FDI) on economic growth in Nigeria for the period 1980. The paper employed ARDL Approach to...

51- Selma KURTISHI-KASTRATI, The Effects of Foreign Direct Investments for Host Country's Economy, American University of the Middle East, Faculty of Business,, Vol. 5 , Issue 1, Kuwait, 2013, Pp2. 